\title{
An Evaluation of Innovative Sweat-Based Drug Testing Techniques for Use in Criminal Justice Drug Testing
}

\section{Dennis J. Crouch}

University of Utah

Center for Human Toxicology

Salt Lake City, UT 84112

Dr. Royer F. Cook

Dr. James V. Trudea

David C. Dove

Institute for Social Analysis

201 North Union Street

Alexandria, VA 22314

Coordination by

U.S. DEPARTMENT OF COMMERCE

Ofifice of Law Enforcement Standards

National Institure of Standards

and Technology

Gaithersburg, MD 20899-8102
QC

100

. $\mathrm{U56}$

\#6825

2002 


\title{
ABOUT THE LAW ENFORCEMENT AND CORRECTIONS STANDARDS AND TESTING PROGRAM
}

The Law Enforcement and Corrections Standards and Testing Program is sponsored by the Office of Science and Technology of the National Institute of Justice (NIJ), U.S. Department of Justice. The program responds to the mandate of the Justice System Improvement Act of 1979, which directed NIJ to encourage research and development to improve the criminal justice system and to disseminate the results to Federal, State, and local agencies.

The Law Enforcement and Corrections Standards and Testing Program is an applied research effort that determines the technological needs of justice system agencies, sets minimum performance standards for specific devices, tests commercially available equipment against those standards, and disseminates the standards and the test results to criminal justice agencies nationally and internationally.

The program operates through:

The Law Enforcement and Corrections Technology Advisory Council (LECTAC), consisting of nationally recognized criminal justice practitioners from Federal, State, and local agencies, which assesses technological needs and sets priorities for research programs and items to be evaluated and tested.

The Office of Law Enforcement Standards (OLES) at the National Institute of Standards and Technology, which develops voluntary national performance standards for compliance testing to ensure that individual items of equipment are suitable for use by criminal justice agencies. The standards are based upon laboratory testing and evaluation of representative samples of each item of equipment to determine the key attributes, develop test methods, and establish minimum performance requirements for each essential attribute. In addition to the highly technical standards, OLES also produces technical reports and user guidelines that explain in nontechnical terms the capabilities of available equipment.

The National Law Enforcement and Corrections Technology Center (NLECTC), operated by a grantee, which supervises a national compliance testing program conducted by independent laboratories. The standards developed by OLES serve as performance benchmarks against which commercial equipment is measured. The facilities, personnel, and testing capabilities of the independent laboratories are evaluated by OLES prior to testing each item of equipment, and OLES helps the NLECTC staff review and analyze data. Test results are published in Equipment Performance Reports designed to help justice system procurement officials make informed purchasing decisions.

Publications are available at no charge through the National Law Enforcement and Corrections Technology Center. Some documents are also available online through the Internet/World Wide Web. To request a document or additional information, call 800-248-2742 or 301-519-5060, or write:

\author{
National Law Enforcement and Corrections Technology Center \\ P.O. Box 1160 \\ Rockville, MD 20849-1160 \\ E-Mail: asknlectc@nlectc.org \\ World Wide Web address: http:/hwww.nlectc.org
}

This document is not intended to create, does not create, and may not be relied upon to create any rights, substantive or procedural, enforceable at law by any party in any matter civil or criminal.

Opinions or points of view expressed in this document represent a consensus of the authors and do not necessarily represent the official position or policies of the U.S. Department of Justice. The products and manufacturers discussed in this document are presented for informational purposes oniy and do not constitute product approval or endorsement by the U.S. Department of Justice.

The National Institute of Justice is a component of the Office of Justice Programs, which also includes the Bureau of Justice Assistance, the Bureau of Justice Statistics, the Office of Juvenile Justice and Delinquency Prevention, and the Office for Victims of Crime. 


\section{An Evaluation of Innovative Sweat-Based Drug Testing Techniques for Use in Criminal Justice Drug Testing}

Dennis J. Crouch

University of Utah

Center for Human Toxicology

Salt Lake City, UT 84112

\section{Dr. Royer F. Cook} Dr. James V. Trudea David C. Dove

Institute for Social Analysis 201 North Union Street Alexandria, VA 22314

Coordination by U.S. DEPARTMENT OF COMMERCE Office of Law Enforcement Standards National Institute of Standards and Technology Gaithersburg, MD 20899-8102

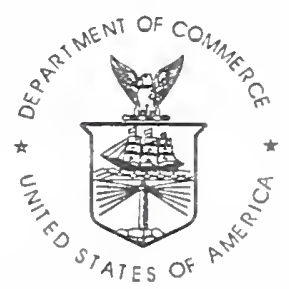

U.S. DEPARTMENT OF COMMERCE Donald L. Evans, Secretary

TECHNOLOGY ADMINISTRATION

Phillip J. Bond, Under Secretary for Technology 


\section{ACKNOWLEDGMENTS}

The technical effort to develop this report was conducted under Interagency Agreement 94-IJ-R004, Project No. 99-002IA.

This research was done under Grant Award Number 60NANB9D0050 from the National Institute of Standards and Technology (NIST) to the Institute of Social Analysis (ISA).

This report was prepared by the Office of Law Enforcement Standards (OLES) of NIST under the direction of Alim A. Fatah, Program Manager for Chemical Systems and Materials, and Kathleen M. Higgins, Director of OLES. 


\section{FOREWORD}

The Office of Law Enforcement Standards (OLES) of the National Institute of Standards and Technology (NIST) furnishes technical support to the National Institute of Justice (NIJ) program to strengthen law enforcement and criminal justice in the United States. OLES's function is to conduct research that will assist law enforcement and criminal justice agencies in the selection and procurement of quality equipment.

OLES is: (1) Subjecting existing equipment to laboratory testing and evaluation, and (2) conducting research leading to the development of several series of documents, including national standards, user guides, and technical reports.

This document covers research conducted by OLES under the sponsorship of the National Institute of Justice. Additional reports as well as other documents are being issued under the OLES program in the areas of protective clothing and equipment, communications systems, emergency equipment, investigative aids, security systems, vehicles, weapons, and analytical techniques and standard reference materials used by the forensic community.

Technical comments and suggestions concerning this report are invited from all interested parties. They may be addressed to the Office of Law Enforcement Standards, National Institute of Standards and Technology, 100 Bureau Drive, Stop 8102, Gaithersburg, MD 20899-8102.

Kathleen M. Higgins, Director

Office of Law Enforcement Standards 



\section{CONTENTS}

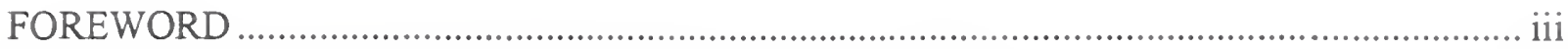

COMMONLY USED SYMBOLS AND ABBREVIATIONS ..............................................vi

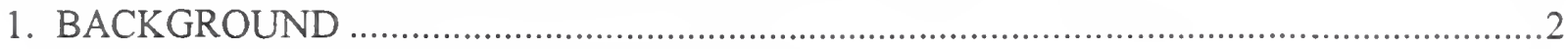

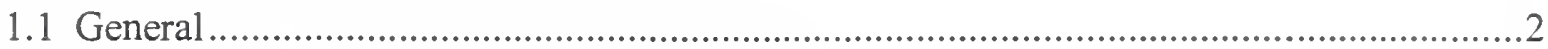

1.2 Drug Testing in the Criminal Justice System................................................................2

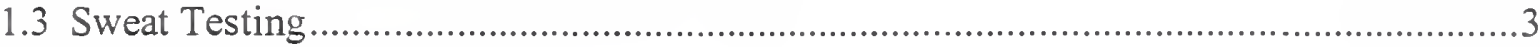

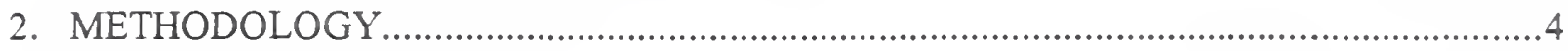

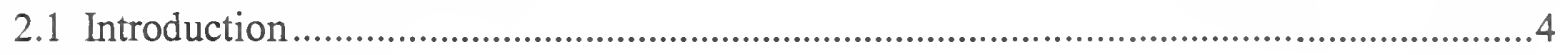

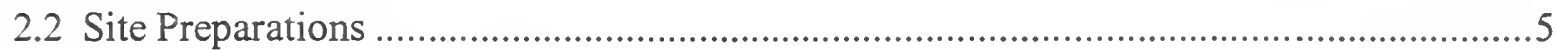

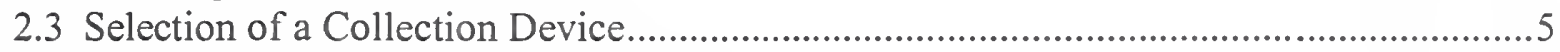

2.4 Modification of the Collection Device ............................................................................

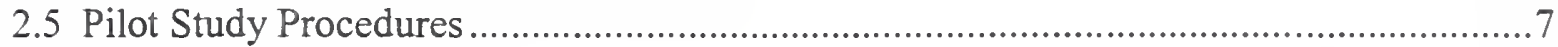

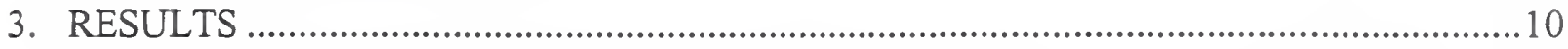

3.1 Collection of Liquid Perspiration: Volumes and Rates ................................................10

3.2 Participant Perceptions of Collection Methods................................................................. 12

3.3 Methods Development: Drug Screening ............................................................................14

3.4 Methods Development: MS Confirmations .................................................................15

3.5 Results: Biological Specimens....................................................................................17

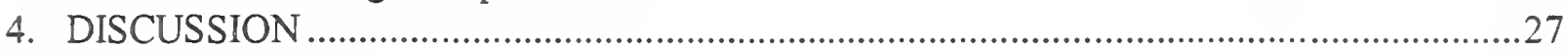

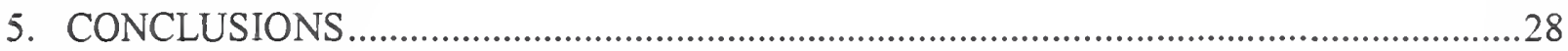

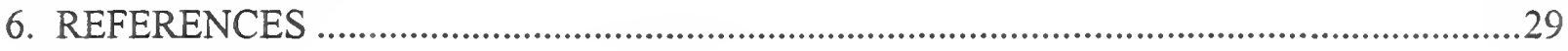

\section{FIGURES}

Figure 1. Liquid perspiration volumes collected......................................................................11

Figure 2. Liquid perspiration collection rates ........................................................................12

Figure 3. Session perceptions..............................................................................................13

\section{TABLES}

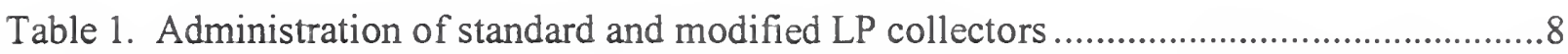

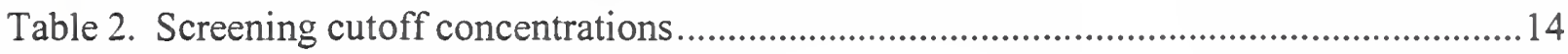

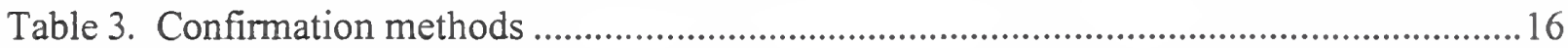

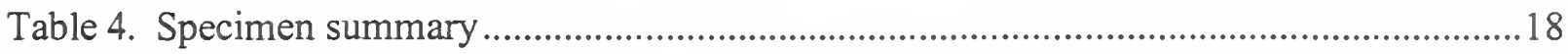

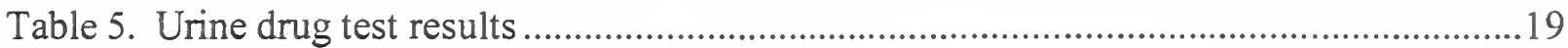

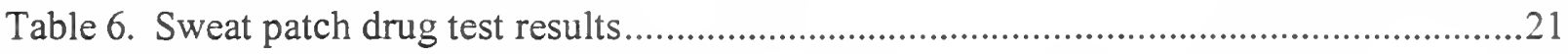

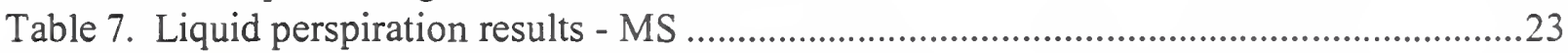

Table 8. Liquid perspiration screen only drug test results .......................................................24

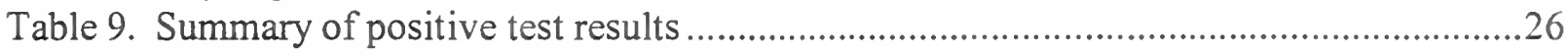




\section{COMMONLY USED SYMBOLS AND ABBREVIATIONS}

\begin{tabular}{|c|c|c|c|c|c|}
\hline A & ampere & $\mathrm{H}$ & henry & $\mathrm{nm}$ & nanometer \\
\hline$A C$ & alternating current & $\mathrm{H}$ & hour & No. & number \\
\hline $\mathrm{AM}$ & amplitude modulation & $\mathrm{Hf}$ & high frequency & o.d. & outside diameter \\
\hline $\mathrm{Cd}$ & candela & $\mathrm{Hz}$ & hertz & $\Omega$ & ohm \\
\hline $\mathrm{Cm}$ & centimeter & i.d. & inside diameter & p. & page \\
\hline $\mathrm{CP}$ & chemically pure & $\ln$ & inch & $\mathrm{Pa}$ & pascal \\
\hline$c / s$ & cycle per second & $1 \mathrm{R}$ & infrared & pe & probable error \\
\hline d & day & $\mathrm{J}$ & joule & pp. & pages \\
\hline $\mathrm{dB}$ & decibel & L & lambert & $\mathrm{ppm}$ & parts per million \\
\hline DC & direct current & L & liter & qt & quart \\
\hline${ }^{\circ} \mathrm{C}$ & degree Celsius & $\mathrm{Lb}$ & pound & $\mathrm{rad}$ & radian \\
\hline${ }^{\circ} \mathrm{F}$ & degree Fahrenheit & Lbf & pound-force & rf & radio frequency \\
\hline diam & diameter & lbf'in & Pound-force inch & $\mathrm{rh}$ & relative humidity \\
\hline emf & electromotive force & $\mathrm{Lm}$ & Lumen & s & second \\
\hline eq & equation & $\mathrm{Ln}$ & Logarithm (base e) & $\mathrm{SD}$ & standard deviation \\
\hline$F$ & farad & Log & Logarithm (base 10) & sec. & section \\
\hline fc & footcandle & $M$ & Molar & SWR & standing wave ratio \\
\hline fig. & figure & M & Meter & uhf & ultrahigh frequency \\
\hline FM & frequency modulation & $\min$. & Minute & UV & ultraviolet \\
\hline $\mathrm{ft}$ & foot & $\mathrm{mm}$ & Millimeter & V & volt \\
\hline $\mathrm{ft} / \mathrm{s}$ & foot per second & $\mathrm{mph}$ & Mile per hour & vhf & very high frequency \\
\hline$g$ & acceleration & $\mathrm{m} / \mathrm{s}$ & Meter per second & W & watt \\
\hline g & gram & $\mathrm{N}$ & Newton & $\lambda$ & wavelength \\
\hline gr & grain & $\mathrm{N} \cdot \mathrm{m}$ & Newton meter & $w t$ & weight \\
\hline
\end{tabular}

area $=\mathrm{unit}^{2}$ (e.g., $\mathrm{ft}^{2}, \mathrm{in}^{2}$, etc. $)$; volume $=\mathrm{unit}^{3}$ (e.g., $\mathrm{ft}^{3}, \mathrm{~m}^{3}$, etc. $)$

\section{PREFIXES}

$\begin{array}{llll}\mathrm{d} & \text { deci }\left(10^{-1}\right) & \mathrm{da} & \text { deka }(10) \\ \mathrm{c} & \text { centi }\left(10^{-2}\right) & \mathrm{h} & \text { hecto }\left(10^{2}\right) \\ \mathrm{m} & \text { milli }\left(10^{-3}\right) & \mathrm{k} & \text { kilo }\left(10^{3}\right) \\ \mu & \text { micro }\left(10^{-6}\right) & \mathrm{M} & \operatorname{mega}\left(10^{6}\right) \\ \mathrm{n} & \text { nano }\left(10^{-9}\right) & \mathrm{G} & \text { giga }\left(10^{9}\right) \\ \mathrm{p} & \text { pico }\left(10^{-12}\right) & \mathrm{T} & \text { tera }\left(10^{12}\right)\end{array}$

\section{COMMON CONVERSIONS}

(See ASTM E380)

$0.30480 \mathrm{~m}=1 \mathrm{ft}$
$25.4 \mathrm{~mm}=1 \mathrm{in}$
$0.4535924 \mathrm{~kg}=1 \mathrm{lb}$
$0.06479891 \mathrm{~g}=1 \mathrm{gr}$
$0.9463529 \mathrm{~L}=1 \mathrm{qt}$
$3600000 \mathrm{~J}=1 \mathrm{~kW} \cdot \mathrm{hr}$

$4.448222 \mathrm{~N}=1 \mathrm{lbf}$ $1.355818 \mathrm{~J}=1 \mathrm{ft} \cdot \mathrm{lbf}$ $0.1129848 \mathrm{~N} \cdot \mathrm{m}=1 \mathrm{lbf} \cdot$ in $14.59390 \mathrm{~N} / \mathrm{m}=1 \mathrm{lbf} / \mathrm{ft}$ $6894.757 \mathrm{~Pa}=1 \mathrm{lbf} / \mathrm{in}^{2}$ $1.609344 \mathrm{~km} / \mathrm{h}=1 \mathrm{mph}$

Temperature: $\mathrm{T}_{{ }^{\circ} \mathrm{C}}=\left(\mathrm{T}_{\circ}{ }_{\circ}-32\right) \times 5 / 9$

Temperature: $\mathrm{T}_{{ }_{\mathrm{F}} \mathrm{F}}=\left(\mathrm{T}_{{ }^{\circ} \mathrm{C}} \times 9 / 5\right)+32$ 


\section{An Evaluation of Innovative Sweat-Based Drug Testing Techniques for Use in Criminal Justice Drug Testing}

Dennis J. Crouch, University of Utah, Center for Human Toxicology, Salt Lake City, UT 84112; and Dr. Royer F. Cook, Dr. James V. Trudeau, and David C. Dove, Institute for Social Analysis, 201 North Union Street, Alexandria, VA 22314.

This Interim Report describes progress to date of the project, "An Evaluation of Innovative Sweat-Based Drug Testing Techniques for Use in Criminal Justice Drug Testing." This threeyear project is a collaborative effort between the Institute for Social Analysis (ISA), the prime contractor, and the University of Utah's Center for Human Toxicology (CHT), the subcontractor.

This project is assessing the feasibility of adapting a device originally designed to collect liquid perspiration from infants to test for cystic fibrosis (the Macroduct) for use in criminal justice settings to test for drug use (as an alternative to urinalysis and the sweat patch). The primary focus of this report is a pilot study that compared liquid perspiration test results to urinalysis and sweat patch results, and obtained participant perceptions of the different collection methods. The pilot study was conducted at the Pre-Trial Services Agency (PSA) in Washington, DC, in April 2000.

ISA and CHT would like to acknowledge Wayne Barlow, President; Kent Thomas, Business Manager; Lewis Webster, Senior Scientist; and Dennis Briscoe, Chief Engineer from Wescor, Inc., for their assistance in planning the project, modifying the collector, and their scientific consultation. We would also like to acknowledge the cooperation and support of Mr. Jerome Robinson and his staff from the PSA. Without the support, cooperation and consultation provided by Wescor, Inc., and PSA, this pilot study could not have been successfully completed. 


\section{BACKGROUND}

\subsection{General}

After a brief overview of the project, this section describes the rationale for the project and reviews pertinent research on drug testing in criminal justice settings.

The project began on May 24, 1999, and will be conducted over a period of three years. Project objectives are as follows:

- Modify and test innovative, less invasive liquid perspiration (LP) collection devices. ${ }^{1}$

- Adapt drug screening kits for use in analyzing LP samples and develop drug confirmation methods.

- Assess the validity and utility of the LP collection device as a method of drug testing with criminal justice populations.

The project is being conducted in conjunction with the Pre-Trial Services Agency in Washington, DC. This agency, a pioneer in the applications of drug testing to criminal populations, currently drug tests approximately 155000 urine specimens annually using an in-house high-speed autoanalyzer. They are an ideal field study site because they test several hundred arrestees daily, the majority of whom test positive for one or more drugs; and they have previously participated in field test trials of innovative drug tests.

\subsection{Drug Testing in the Criminal Justice System}

Drug testing is now widely used throughout the criminal justice system. Major uses include: (1) the Arrestee Drug Abuse Monitoring (ADAM) system (an expansion and refinement of the Drug Use Forecasting - DUF program), by which samples of arrestees in sites around the country are tested to estimate drug use prevalence in the arrestee population (NIJ, 1996) ${ }^{2}$; (2) pretrial drug testing, used to make decisions about probation or pretrial release, and to supervise drug-involved defendants more closely (Visher, 1992); (3) post-adjudication testing of drug offenders by probation and parole departments (Turner, et al., 1994); and (4) testing of law enforcement personnel (Reaves, 1992). In addition to these major programs, drug testing is also a significant element in drug courts (Goldkemp and Weiland, 1993) and in programs designed to assess drug use among juvenile detainees (Dembo et al., 1990). Moreover, data on the effectiveness of drug testing is sufficiently supportive that testing is likely to expand throughout the criminal justice system (Mieczkowski and Lersch, 1997).

Currently, most drug testing in criminal justice is based on analysis of urine specimens by immunoassay (screening) and gas chromatography/mass spectrometry (GC/MS) (confirmation). Although recently alternative testing techniques such as hair analysis and on-site kits have become

\footnotetext{
'Certain commercial equipment, instruments, or materials are identified in this paper to adequately speeify the experimental procedure. Such identification does not imply recommendation or endorsement by the National Instifute of Standards and Technology (NIST), nor does it imply that the equipment, instruments, or materials are necessarily the best available for the purpose.

${ }^{2}$ Items in parentheses refer to References in section 6.
} 
more common (NIJ, 1996), the laboratory-based methods remain the "gold standard" by which other methods are assessed. However, despite its advantages, urine testing involves collection methods that are invasive - often discomfiting to donor and collector alike - and which typically require burdensome facilities and procedures. It would be highly desirable to develop a practical, cost-effective method of drug testing that is as accurate as urine testing, but less invasive. Among the alternative technologies that are in various stages of development are hair analysis, perspiration analysis, and saliva analysis. Hair analysis is perhaps the most advanced of these technologies; several commercial laboratories are now performing hair analysis, and researchers have begun to test its efficacy in criminal justice settings (Mieczkowski, 1993). However, because of potential problems with contamination and hair color bias, the accuracy and utility of hair analysis remain in question, (Cook et al., 1996; and NIJ, 1996). In principle, the analysis of other body fluids perspiration and saliva - should offer the most promising noninvasive means of drug testing.

Several devices are now available for saliva testing; however, little is known about the utility of these devices or how drugs and their metabolites are transferred from blood to saliva. In addition, immediately after smoking or orally ingesting a drug, the oral cavity may be contaminated by the drug leading to falsely elevated saliva-drug concentrations. Also, drug concentrations in saliva appear to vary by collection method (O'Neal, et al., 2000). Therefore, among the less invasive methods, sweat testing appears the most promising. Moreover, new liquid perspiration collection devices appear to be promising noninvasive means of drug testing. These techniques are discussed below.

\subsection{Sweat Testing}

Sweat collection devices have been approved for clinical applications and for drugs of abuse testing. Amphetamine and methamphetamine, heroin, morphine, methadone, and phencyclidine have all been detected in sweat (Baer and Booher, 1994). Sweat may be collected on tamper proof absorbent patches. The patches are applied to the subject with a simple adhesive and may be worn for extended periods of time. While the patch is worn, sweat is absorbed and drug(s) and their metabolite(s) are deposited on it. Several studies have been performed to evaluate the efficacy of detecting drug use with sweat patch testing (Burns, 1995; Fogerson, et al., 1997; and Kintz, 1996). These studies have shown that the patches are particularly useful in criminal justice settings where constant surveillance through use of the sweat patch has detected drug use that was not detected using discrete urinalysis tests. The patches are also potentially useful in drug treatment and parole/probation programs where abstinence is a measure of treatment compliance and recidivism can be monitored by having the patient continuously wear a patch.

A potential problem with sweat testing is that little is known about the deposition of drugs into sweat, therefore, interpreting the test result is difficult. In addition, for most drugs, we do not know the minimum dose that would need to be ingested for the drug to be detected in the patch. Currently, we cannot predict how long after ingestion drugs of abuse can be detected in liquid perspiration.

The actual volume of sweat collected by the patch is unknown. This precludes meaningful (drug/microliter $(\mu \mathrm{L})$ of LP) quantitative analysis of drugs detected and limits the interpretative 
value of the results. The cost of testing a sweat patch is about the same as urinalysis testing. However, since drug concentrations are lower and the entire patch is consumed for a single conformational analysis, repeat testing and confirmation of multiple drug use are precluded. The Webster Sweat Collection System was introduced in 1978 (Webster, 1981). This was one of the first systems designed to collect liquid perspiration. The system is currently designed to harvest LP samples from infants for use in the early diagnosis of cystic fibrosis (Carter, 1981; and Hammond, 1994). The system consists of pilocarpine discs that stimulate the sweat glands, a portable power supply that provides a micro current to induce "iontophoresis", and the LP collection device. Pilocarpine is a naturally occurring alkaloid that can be extracted from plants and is used medically to treat glaucoma. In addition, it stimulates salivation and sweating. In the collection process, iontophoresis provides a small electrical current (microamps) that promotes transfer of the ionized pilocarpine through the skin to the sweat glands stimulating sweat production. There are several potential advantages to the use of the LP for drug testing in the criminal justice system. First, sensible sweat is collected. This LP is actively produced at the time of collection and, therefore, the drug concentrations may be reflective of blood drug concentrations. The system has Food and Drug Administration (FDA) approval and has been designed for use with infants and children. Therefore, it is extremely safe for both the collector and the donor. The entire system is compact and portable $(9.2 \mathrm{~cm} \times 4.5 \mathrm{~cm} \times 15.5 \mathrm{~cm}$, weighs $0.4 \mathrm{~kg})$, and fits into a carrying case no larger than that used for a laptop computer. Therefore, mobile collections are feasible and no special facilities are needed. The collector can observe this entire collection process. The collection device is attached to the donor's forearm and a capillary tube fills with LP by hydrostatic pressure, thereby ensuring the integrity and identity of the sample. The collection of LP with this device also has advantages for drug analysis and interpretation. A significant potential advantage over the sweat patch is that liquid samples can be analyzed at the site of collection by laboratory based immunoassay tests or by on-site test kits. The drug content in liquid samples can also be quantified such that drug test results can be reported in concentration $\mu \mathrm{L}$ of LP, improving the potential for meaningful interpretation.

However, there are also disadvantages to the current version of the collection device. The price currently exceeds that of patch testing (\$7/sweat collection vs. \$5/sweat patch). An initial investment of $\$ 1575$ is needed for the power supply. A second disadvantage is that collection of $50 \mu \mathrm{L}$ to $60 \mu \mathrm{L}$ of LP may take $10 \mathrm{~min}$ to $15 \mathrm{~min}$ - although such times are not that much in excess of the time required for a urine collection. A third disadvantage is that the device is designed for micro-collection and the volume of LP collected may limit the type and number of analysis that can be performed on each specimen. These potential disadvantages are being addressed in the ongoing project.

\section{METHODOLOGY}

\subsection{Introduction}

Four important aspects of the study methodology are discussed: (1) preparations, (2) liquid perspiration (LP) collection device selection, (3) pilot test data collection procedures, and (4) analytical procedures developed to test the specimens collected during the pilot study. 


\subsection{Site Preparations}

Given the developmental nature of this project, initial meetings and preparation were important for laying the groundwork for the study. These meetings were critical in finalizing the study design, selecting and modifying the LP collection device, and planning the pilot study.

\subsection{Selection of a Collection Device}

Sweat has been extensively studied as a potential diagnostic fluid and several sweat collection methods are described in the literature. Skin blotting, skin wipes, capillary tubes, sweat patches, and iontophoresis have been evaluated (Kidwell et al., 1998). Techniques such as blotting and skin wipes often rely on occlusive sweat stimulation and collection. The limb or site of collection is placed in an impermeable environment such as a plastic bag. Sweat produced by the limb is trapped in the occlusive bag. Then the skin can be blotted with an absorbent material or wiped with a specially designed absorbent skin wipe. The quantity of sweat collected is estimated by comparing the precollection and post-collection weights of the blotter or wipe. Also, LP can be harvested from the occlusive bag using a calibrated capillary tube. Nonocclusive LP collection techniques have also used blotters, skin wipes and capillary tubes. Sweat is harvested from perspiration that accumulates on the skin. Different absorbent materials such as gauze and specially formulated materials have been used for these collections. Blotting and skin wiping have obvious limitations. Physiological materials such as sebum, statium corneum, and drugs or chemicals deposited on the skin may be collected in addition to the LP. Also, the blotters and skin wipes may be inconsistent in texture and weight, making collection time-consuming and problematic.

Capillary tube collections also have limitations. The tubes are fragile and must be graduated by volume. In addition, capillary tube collections rely on having recognizable LP on the skin surface.

Two sweat collection devices showed promise for use in this project: the sweat patch and the LP collection device. The patch is FDA approved for drugs of abuse testing and the LP collection system is FDA approved for clinical applications such as harvesting sweat for the diagnosis of cystic fibrosis. The sweat patch is a nonocclusive collection device that has been developed specifically to harvest perspiration for testing for drugs of abuse. The patches are approximately 2 in $x 3$ in and resemble a large adhesive bandage. The patches have an outer hypoallergenic adhesive layer that is permeable to small molecules, such as water vapor, and an absorbent pad. Each sweat patch has a unique identifier for subject tracking and they are tamper resistant. The patches are attached to the subject's upper arm, chest or lower back and typically are worn for $7 \mathrm{~d}$ to $14 \mathrm{~d}$. While the patch is worn, drug(s) and their metabolite(s) in the sweat are deposited on the pad. Several studies have been performed to evaluate the efficacy of detecting drug use with sweat patch testing (Burns, 1995; Fogerson, 1997; and Kintz, 1996). These studies have shown that the patches are particularly useful in criminal justice settings. Despite its advantages, there are several problems with the sweat patch. The volume of sweat deposited on the patch is not known, therefore, equating a positive drug test result to dose or time since use is problematic. The extent of sweating affects the amount of sweat produced by the subject, the amount of LP collected by the patch, and the amount of drug deposited on the device. For most drugs, the minimum dose that would need to be ingested for the drug to be detected on the patch is not known. Also, it cannot currently be predicted how long (after ingestion) most drugs can be detected in the sweat patch. A 
major disadvantage of sweat patch testing is that (despite the manufacturer's claims) the patch does not collect insensible perspiration (passive loss of water vapor through the skin by diffusion). The cost of sweat patch testing is about the same as urinalysis testing. However, since drug concentrations are low and the entire patch is consumed for a single conformational analysis, repeat testing to ensure accuracy and confirmation of multiple drug use are precluded.

There are also disadvantages to the existing version of the LP collection system. The major disadvantages are that it collects $<100 \mu \mathrm{L}$ of sweat and the collection takes $10 \mathrm{~min}$ to $20 \mathrm{~min}$. Although the collection time appears protracted, it is not that much longer than the time required for a urine collection when custody and control forms must be completed. The collection volume is a problem given that drug screening usually requires $10 \mu \mathrm{L}$ to $50 \mu \mathrm{L}$ of sample/drug and MS confirmations typically require at least 1 milliliter $(\mathrm{mL})$ of sample/drug.

\subsection{Modification of the Collection Device}

Prior to the pilot study, LP specimens were collected in-house with the current system (using informed consent). Collections typically took about $30 \mathrm{~min}$ and approximately $60 \mu \mathrm{L}$ of LP was collected. Some participants produced less than a complete sample in that time. It was important to keep the collection time to a length that would be acceptable by criminal justice practitioners and donors and to maximize the volume of LP collected, so alternative methods were explored to increase the rate of LP collection.

Through discussions with the manufacturer, four strategies were proposed:

1. Increase the pilocarpine concentration in the induction disks. The expected advantage was to decrease the induction time from about $5 \mathrm{~min}$ to perhaps $2.5 \mathrm{~min}$. The expected disadvantages were that there is a point of diminishing returns where further induction does not result in an increase in LP production, and any time saving would be relatively small because the collection takes substantially longer than the induction.

2. Increase the induction voltage, thereby increasing the iontophoresis current. The expected advantage was to increase volume of liquid perspiration produced through the incorporation of more pilocarpine. The expected disadvantage was that there is a critical voltage above which further increases will cause discomfort to the subject.

3. Use more than one collection device. The expected advantage was to increase the total LP volume collected. The expected disadvantages were that the end-users would need to purchase multiple devices, the collection would be more complicated, and participants might be reluctant to have multiple devices applied.

4. Modify the collection device. The expected advantage was to increase the skin surface area covered by the device and to increase the volume of LP collected per unit time. The disadvantage was that this alternative would be more costly in the short term. 
We attempted to increase the current and decrease the iontophoresis time and determine the effect on volume collected, collection time, and subject discomfort. This resulted in an increased collection time, apparently because less pilocarpine reached the sweat glands. Therefore, the decision was made to accept a more-costly alternative of modifying the collector, which seemed to hold the most promise in the long term. Under subcontract, the manufacturer developed a prototype of the collector with larger induction and collection surface areas.

\subsection{Pilot Study Procedures}

\subsubsection{Collection Procedures}

Data were collected onsite at a pretrial agency satellite office that served several hundred clients daily. Data collection occurred during regular office hours over a 3-week period in April and May 2000. All arrestees who were required to report to the satellite site for drug testing were eligible to participate in the project, and a $\$ 20$ cash stipend was provided. Thirty-two arrestees participated in the pilot study. This sample size was judged sufficient for a preliminary assessment of the LP collection devices, since it was likely that a sizable proportion of the specimens collected would be drug-positive.

Written informed consent was obtained from each participant. The informed consent advised participants that their questionnaire responses and drug test results would be confidential, and that the test results would not be used against them in any legal proceeding. Additionally, researchers and agency staff emphasized that the test results would not affect participant involvement in their pretrial obligations.

The pilot study involved two sessions of data collection that were one week apart. During session 1 , a sweat patch was applied to each participant, and he or she provided a urine sample and one or two LP specimens. In many cases, the participant had just provided a urine specimen for the pretrial agency; these subjects were not asked to provide an additional specimen for the study. Instead, an aliquot from the agency's specimen was obtained. For the other participants, a trained technician followed the standard agency protocol for urine collection.

LP collection began with an introduction to the equipment and procedures, and an opportunity for participants to have any questions or concerns addressed. Then LP collection using either the standard or modified collector commenced. Two electrodes with gel-discs containing pilocarpine nitrate were attached to the participant's lower arm. A low-level current was passed through the pilocarpine disks into the skin inducing the sweat glands to produce liquid perspiration. The induction period lasted approximately $5 \mathrm{~min}$. The induction period for the modified collector, with its larger electrodes and pilocaropine disks, lasted only $2 \mathrm{~min}$. After the induction period, a standard or modified LP collection device was placed over the area of the skin where the induction had occurred. Both collection devices resembled watches, with a wristband securely attaching the device to the subject's arm. The LP was collected into a spiral-microbore tube that was part of the collector. Throughout the process, the research assistant adhered strictly to the manufacturer's instructions for collection. 
During the initial session, a sweat patch was applied to the lower ribcage or upper arm of each participant. Participants were asked to leave the patch in place for one week and were given instructions for care. Again, the manufacturer's instructions were followed explicitly.

At the conclusion of the LP collection, both the volume of LP collected and the collection time were recorded. The LP specimens were then transferred into glass storage vials and the vials were labeled with a unique study identification number. After specimen collection and sweat patch application, participants completed a brief questionnaire about their recent drug use and their perceptions of the collection procedures.

The questionnaire asked participants to rate the standard LP collector, the modified collector, and the urinalysis collection procedure on four dimensions: discomfort, lengthiness of collection, unpleasant sensations, and embarrassment. Participants were asked to rate the sweat patch only at session 2, when the patch was harvested. Ratings were made on a 3-point scale, with 3 being the most negative response. Participants were also asked which procedure they liked most and which they liked least. The final section of the questionnaire asked participants to report how frequently they had used a variety of illicit drugs in the last 30 days and how recently they had used the drugs.

Participants were scheduled to return approximately one week later for session 2 specimen collections. Participants were told that they would again receive the incentive $(\$ 20)$ for completing session 2. Of the 32 session 1 participants, $23(72 \%)$ returned for session 2. Each returning participant provided session 2 urine and LP specimens, the sweat patch was harvested, and they completed a second drug use and perceptions questionnaire.

Not all subjects provided a full compliment of specimens. Thirty-two urine specimens were collected at session 1 and 23 specimens were collected at session 2 . Of the 23 participants who participated at session 2, 20 returned sweat patch specimens (69\% of the total sample). During the two sessions, the standard LP collector was administered to all participants at least once. However, the modified LP collector was only administered to a portion of the subjects due to a limited supply of the prototype devices. The following table summarizes the LP collections at sessions 1 and 2. Thirty participants received the standard collection at session 1 and 15 at session 2 . Seventeen participants received the modified collection at session 1 and 13 at session 2. Fifteen participants were administered both LP collection procedures at session 1, and 6 received both at session 2 .

Table 1. Administration of standard and modified LP collectors

\begin{tabular}{|l|c|c|c|}
\hline \multicolumn{1}{|c|}{$\begin{array}{c}\text { Device } \\
\text { Administered }\end{array}$} & Session 1 & Session 2 & Total \\
\hline Standard alone & 15 & 9 & 25 \\
\hline Modified alone & 2 & 7 & 9 \\
\hline Standard and modified & 15 & 6 & 21 \\
\hline Did not participate & -- & 9 & 9 \\
\hline
\end{tabular}




\subsubsection{Data and Specimen Handling Procedures}

All specimens were labeled with identification numbers to allow matching of the survey data with the specimen data. Confidentiality of the survey data was maintained throughout the analysis. All specimens were treated as biohazards during collection and handling. The specimens were stored in secure refrigerated vaults, then cold-packed and shipped via overnight courier and identified only by study identification number.

\subsubsection{Selection and Analytical Methods Development}

Potential methods to screen the LP specimens for drugs of abuse were reviewed. Two promising laboratory-based immunoassays were selected: enzyme immunoassay (EIA) and radioimmunoassay (RIA). EIA is a competitive immunoassay in which drug in the urine, or LP, and enzyme-labeled drug in the test kit compete for a limited antibody. A substrate is then added to the test mixture, which the enzyme may react, and the resulting color is read instrumentally (STC, 1996, 1997; and Fay, 1996). RIA is also a competitive immunoassay technique that detects drugs in a similar fashion except the radioactivity of the test solution is measured as an indication of drugs in the sample. Both EIA and RIA test kits are commercially available.

An assessment of the EIA kits for the analysis of LP was performed. Known drug-free LP was collected from laboratory volunteers (see above). These samples were pooled and fortified with drugs of abuse to evaluate the kits. Two calibration curves were prepared. One contained only parent drug and the other drug metabolite. These data were used to establish the limit of detection by EIA, to assess the manufacturers published procedures, and to determine if there were matrix effects from LP.

RIA has been used to test a variety of biological specimens (Crouch, 1983; Smith, 1981; Moody, 1992; and Henderson, 1993). Our testing laboratory has used RIA since the late 1970s to screen urine, serum, plasma, blood, bloodstains, saliva, and tissue homogenates for drugs of abuse. The pooled and fortified LP samples discussed above were used to evaluate the RIA kits for use in testing LP. These data were used to establish the limit of detection, to validate the manufacturers published procedures, and to determine if there were matrix effects from LP.

A major challenge in this research project was to develop confirmation and quantitation methods with the sensitivity and specificity to test sweat patch extracts and LP. The LP analyses were especially challenging because the volume of LP collected was typically in $\mu$ Ls and the expected drug concentration were similar to blood-drug concentrations ( $\mathrm{ng} / \mathrm{mL}$ ). The specimen volume and drug concentrations are in contrast to urine collections that are typically in excess of $100 \mathrm{~mL}$ and urine-drug concentrations may be 10 or more times those of blood-drug concentrations. Standard electron ionization MS methods do not have the sensitivity to confirm drugs of abuse and their metabolites in LP or in sweat patch extracts. Therefore, we focused on developing chemical ionization GC/MS, liquid chromatography/mass spectrometry (LC/MS), and liquid chromatography tandem mass spectrometry (LC/MS/MS) methods. As described, known drug-free LP was collected from laboratory volunteers. These samples were pooled and fortified with drugs of abuse to evaluate potential MS methods. Calibration curves were prepared by fortifying the appropriate 
drug concentrations into the drug-free LP. These data were used to assess assay linearity and sensitivity.

\section{RESULTS}

\subsection{Collection of Liquid Perspiration: Volumes and Rates}

An important goal of the pilot study was to determine how well the standard LP collector, which had previously been used with children, would function when used with adults. The volume of LP collected during each collection session is presented in figure 1 . That figure presents the following data: the volume of LP collected by the standard collector in one session (observations $1-45$ ), the volumes of LP collected by the modified collector in one session (observations $46-76)$, and the total volume of LP collected in sessions where both devices were used (observations $77-98$ ).

The volumes collected with the standard collector ranged from $0 \mu \mathrm{L}$ to $85 \mu \mathrm{L}$ (the maximum capacity) with a mean of $36.4 \mu \mathrm{L}$ and a median of $33.5 \mu \mathrm{L}$. With the modified collector, specimen volumes ranged from $0 \mu \mathrm{L}$ to $199 \mu \mathrm{L}$ with an average of $79.3 \mu \mathrm{L}$ and a median volume of $71.0 \mu \mathrm{L}$. Collection sessions in which both devices were used yielded total volumes of LP ranging from $4 \mu \mathrm{L}$ to $216 \mu \mathrm{L}$ with a mean of $105.1 \mu \mathrm{L}$. It is important to reiterate the time constraints placed on modified LP collection: collection was terminated as soon as the standard collector (administered first) was ready to be removed. Rarely did modified collection proceed for a full $30 \mathrm{~min}$.

The average duration of the LP collection sessions was $29.5 \mathrm{~min}(S D=4.4 \mathrm{~min})$ with the standard collector and $26.5 \mathrm{~min}(S D=3.1 \mathrm{~min})$ with the modified collector. The average collection rates, measured in $\mu \mathrm{L} / \mathrm{min}$, are presented with $95 \%$ confidence intervals in figure 2 . The mean collection rate was $1.2 \mu \mathrm{L} / \mathrm{min}$ at session 1 and $1.4 \mu \mathrm{L} / \mathrm{min}$ at session 2 . As hypothesized, the larger modified collector collected perspiration at a faster rate. For session 1 , the average modified collection rate was $2.7 \mu \mathrm{L} / \mathrm{min}$ and the session 2 mean was $3.3 \mu \mathrm{L} / \mathrm{min}$. 


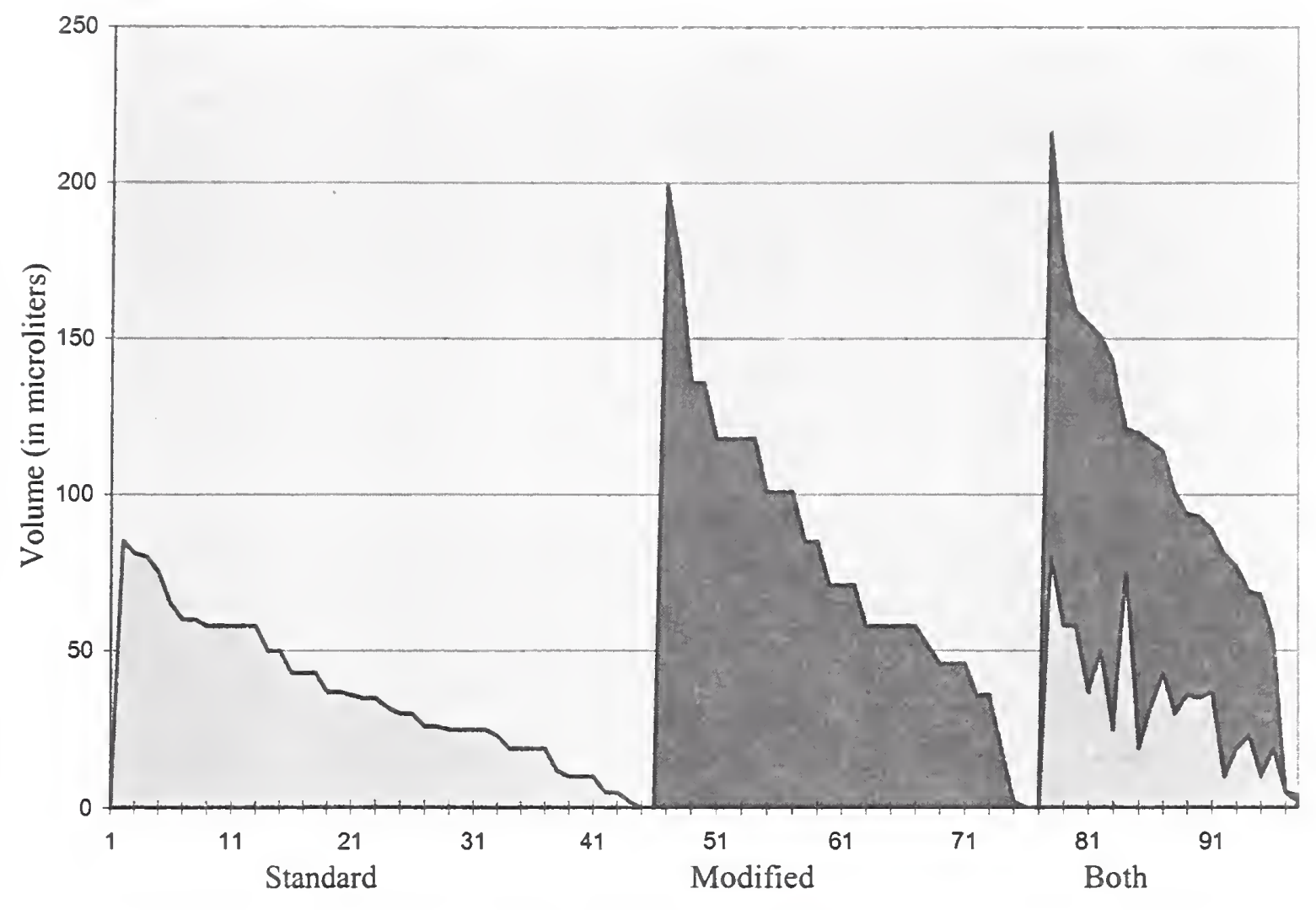

Figure 1. Liquid perspiration volumes collected 
Means and $95 \%$ Confidence Interval

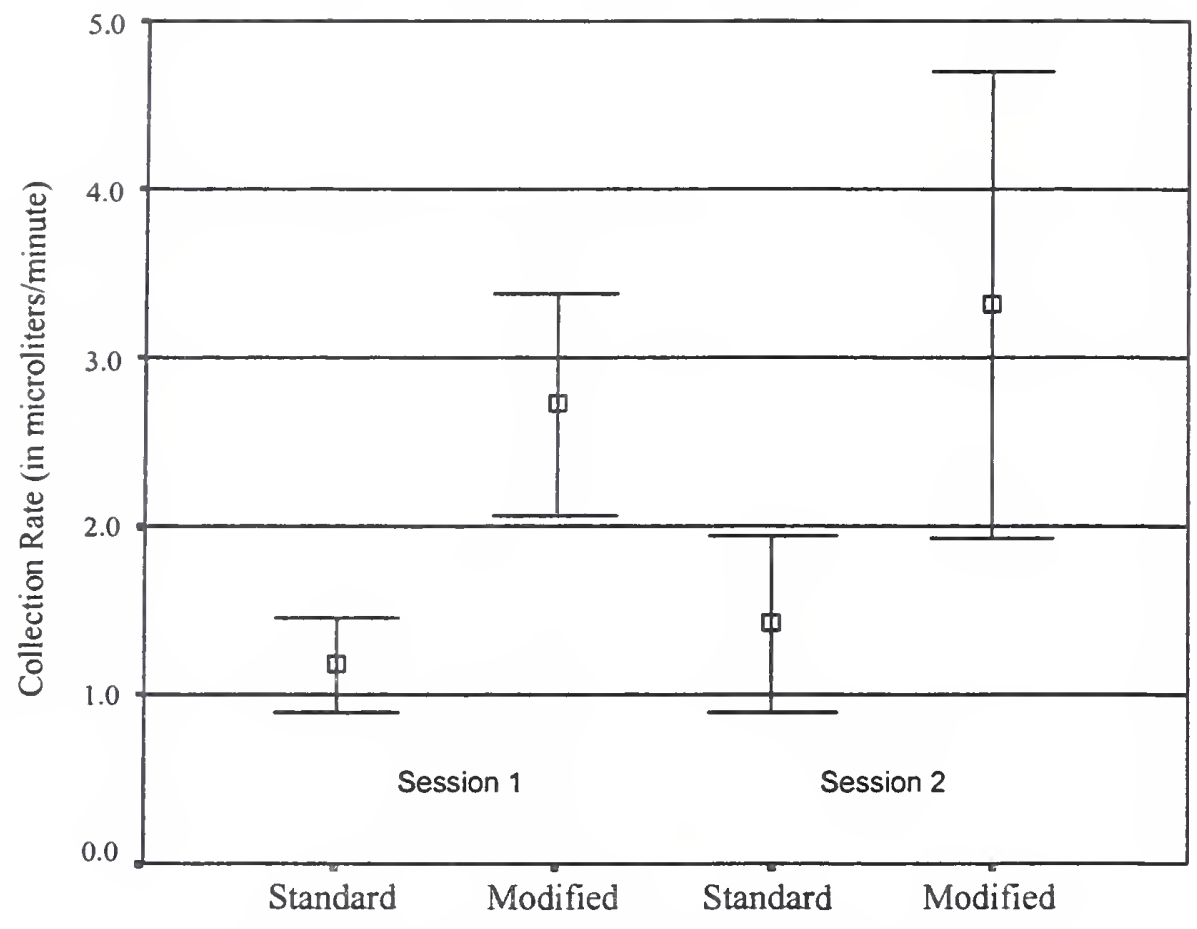

Figure 2. Liquid perspiration collection rates

\subsection{Participant Perceptions of Collection Methods}

Participants rated the specimen collection methods on four dimensions: 1) discomfort, 2) lengthiness of collection, 3) unpleasant sensations, and 4) embarrassment. It was hypothesized that the modified and standard LP collection methods would be perceived as 1) no more uncomfortable than sweat patch or urine collection, 2) no more demanding in time required for administration than sweat patch or urine collection, 3) no more unpleasant sensations than sweat patch or urine collection, and 4) less embarrassing than urine collection.

At session 1, subject perception data were gathered for all methods except the sweat patch. Participant mean ratings are presented in figure 3. Each hypothesis was tested using repeated measures analysis of variance (ANOVA), adjusting the degrees of freedom using Huynh-Feldts' Epsilon in cases where Mauchly's Test of Sphericity (SPSS, 1999) revealed the sphericity assumption was not tenable. Consistent with the first hypothesis, repeated measures ANOVA revealed that the discomfort ratings for the LP collectors and urine did not statistically differ $(F[1.536,23.041]=0.06, n s)$. Likewise, differences in ratings of "lengthiness" were not significant $(F[2,26]=1.13, n s)$. The third hypothesis was supported by an ANOVA in which ratings of "unpleasant sensations" experienced during collection modalities did not demonstrably differ $(F[1.397,20.961]=0.42, n s)$. The ANOVA for "embarrassment" ratings, however, displayed a trend toward significance $(F[1.00,14.00]=4.38, p<0.10)$. This trend offered limited support for the fourth hypothesis; with pairwise comparisons showing that participants rated urine collection as more embarrassing than either of the LP collections. 


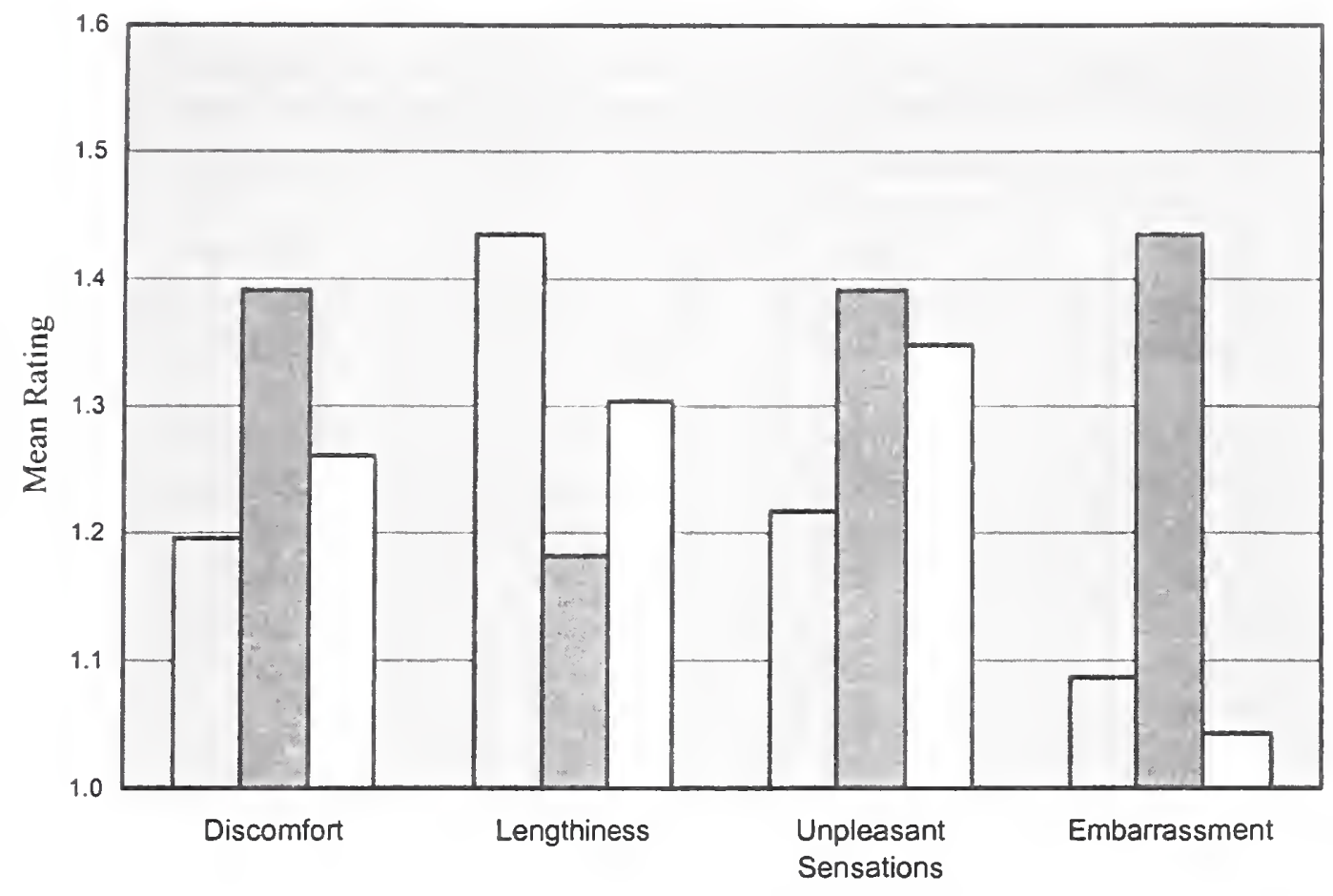

Grey $=$ Liquid perspiration $\quad$ Dark Grey $=$ Urine $\quad$ White $=$ Sweat patch

Figure 3. Session perceptions

Due to the limited sample size that was used at the modified collection at session 1 ( $n=18)$, we averaged the perception ratings for modified and standard collections to create composite LP collector ratings. Within-subject t-tests were conducted to ensure that the LP collector ratings did not demonstrably differ. T-tests suggested that the two devices' ratings were not significantly different on any of the four dimensions (all $t^{\prime} s<|1.75|, n s$ ). In addition, the procedures for administering the modified and standard were very similar, and the correlations between participants ratings of each were .44 and above. Thus, we combined the two sweat collector ratings into a composite. This allowed us to compare perceptions of urine collection to those of LP collection with samples of at least 30 participants for each dimension. T-tests conducted with these data produced results consistent with those discussed above: Urine and LP collection did not differ on "discomfort" or "unpleasant sensations," LP collection was perceived as a significantly lengthier process, and urine collection was rated as significantly more embarrassing.

At session 2, participant perceptions were assessed for all four types of specimen collection. The modified and standard LP collection ratings were again combined to maximize sample size, and analysis of variance was used to compare perceptions of collection methods on each of the four 
dimensions. Consistent with our hypotheses and session 1 findings, no differences in the LP collection, urine collection, and sweat patch collection ratings were found for discomfort or unpleasant sensations. Unlike session 1, at session 2 lengthiness ratings were consistent with our hypothesis, and the analysis did not show any difference in participants' perceptions of how long each method took. On the other hand, the session 1 finding that urine collection was perceived as the most embarrassing modality was replicated: the session 2 embarrassment ANOVA was significant $(F=5.01, p<0.01)$ and a post-hoc Duncan test showed urine collection to be more embarrassing than the LP collectors or the sweat patch.

At each session, participants were asked which collection method they would most like to use again and which method they would least like to use again. Unfortunately, responses to the questions were often invalid (selecting collection methods the respondent had not been administered and selection of multiple responses) or provided contradictory information (one respondent selecting the same collection method as both most and least preferred). Thus no conclusive results were obtained for this portion of the pilot study. Based on the response styles of the pilot test participants, these preferences will be reassessed for valid data collection in the main field test.

\subsection{Methods Development: Drug Screening}

LP was collected from approximately 20 "drug free" subjects and was used as a negative control and to fortify with drugs and drug metabolites. No immunoassay (IA) interferences were observed using the EIA or RIA products when testing LP from these collections. Calibration curves were prepared for the drugs and metabolites in actual LP. The following EIA and RIA test kits were evaluated: THC, cocaine, opiates, PCP, amphetamine, and methamphetamine.

The established immunoassay cutoff concentrations are shown in table 2. The IA was used for screen testing (or drug detection) only and not for quantitative purposes. Therefore, we were most interested in the qualitative cutoff concentration. The EIA test kits showed more promise for drug detection in LP than RIA; specifically, in the detection of THC, THC-COOH, codeine, and morphine. The data were very encouraging since the sensitivities obtained were consistent with those needed to screen for drugs of abuse in LP. The EIA screening cutoff concentrations are shown below.

Table 2. Screening cutoff concentrations

\begin{tabular}{|c|c|c|c|c|c|}
\hline Drug class & Cocaine & Opiates & Amphetamines & Marijuana & PCP \\
\hline & & & & & \\
Cutoff concentration & $5 \mathrm{ng} / \mathrm{mL}$ & $<5 \mathrm{ng} / \mathrm{mL}$ & $5 \mathrm{ng} / \mathrm{mL}$ & $5 \mathrm{ng} / \mathrm{mL}$ & $<5 \mathrm{ng} / \mathrm{mL}$ \\
\hline
\end{tabular}




\subsection{Methods Development: MS Confirmations}

In addition to selecting a suitable screening technique for testing the LP and sweat patch extracts, we explored options for drug/metabolite confirmations. The most promising technologies were GC/MS, LC/MS, and LC/MS/MS. Summaries of the methods developed for LP confirmation testing are shown in table 3. Shown in the table are a summary of the drugs tested, extraction methods, the calibration curve concentrations, and the internal standards.

It was our intention to develop a single LC/MS/MS procedure capable of detecting all the target drugs of abuse and their metabolites in LP. However, this proved more difficult than anticipated. The limitation was in our ability to efficiently ionize THC and THC-COOH by electrospray ionization LC/MS/MS. Presumably, the lack of a functional group that is readily ionized made electrospray ionization inefficient for cannabinoid analysis. Therefore, we developed an alternative method using atmospheric chemical ionization to ionize THC and THC-COOH. However, experiments to date have shown that atmospheric chemical ionization is also far less effective for the ionization of $\mathrm{THC}$ and $\mathrm{THC}-\mathrm{COOH}$ than of the other target drugs and metabolites. We will continue to explore options to combine the analyses into a single MS/MS analysis. The method used to test the samples reported here was negative-ion chemical ionization GC/MS.

To test the hypothesis that the modified device collected LP faster than the original collector, two t-tests were performed. A within-subjects analysis, using observations taken from participants who received both devices at least once, showed that there was a difference between the collection rates of the two devices $(t[26]=5.90, p<.001)$. A between-subjects analysis, using all of the collection rate data regardless of whether or not a participant provided both modified and standard data, also showed that the modified collected LP at a faster rate than the standard $(t[75]=4.93, p<.001)$.

The issue of whether gender, or recent drug use, affected LP collection rates was addressed with standard collection rate data from session 1 . Although the sample included only three females, LP collection rates did not appear to differ between males and females. Collection rates for participants who reported using illicit substances in the past 30 days $(n=10)$ did not differ from participants reporting no use $(n=18)$. Neither replications of these analyses with session 2 data, nor finer-grained analyses, for differences between rates of those who reported using different drugs revealed differences in collection rates. 


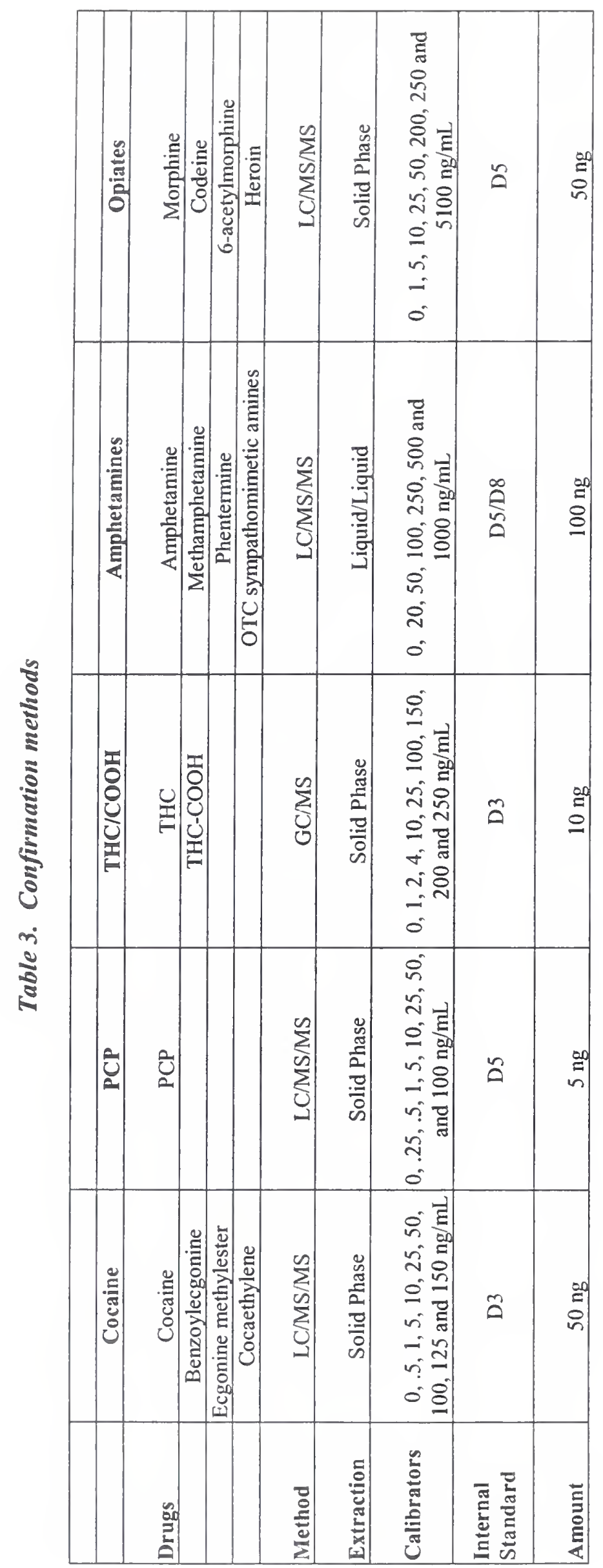




\subsection{Results: Biological Specimens}

\subsubsection{Specimen Summary}

Table 4 (Specimen summary) shows the specimens that were collected from 32 subjects during the pilot study.

\subsubsection{Urine Results}

Results from the urine drug screens and confirmation tests are shown in table 5. The session 1, urine 1 (U1), and session 2, urine 2 (U2) samples were screened for the presence of drugs of abuse using a commercial urinalysis immunoassay. In addition to the tests listed in the proposal, all samples were tested for both amphetamine and methamphetamine. The table shows that one urine specimen screened positive for PCP, two for cannabinoids, five for cocaine, three for opiates, and none for amphetamine or methamphetamine. Using MS, drugs were confirmed in each urine specimen that screened positive. In total, nine urine specimens collected from the 32 subjects tested positive. In subjects $6,8,25$, and 26 , both the U1 and U2 urine specimens contained drugs.

\subsubsection{Sweat Patch Results}

Results from the sweat patch screen and confirmation testing are shown in table 6. Aliquots of the sweat patch extracts were screened for the presence of drugs of abuse using the validated EIA immunoassay as discussed above. The sweat patch extracts were tested for amphetamine(s), PCP, cannabinoids, cocaine, metabolites, and opiates. The table shows that six extracts screened positive for cocaine and four opiates. None screened positive for amphetamine(s), PCP, or cannabinoids. Using MS, drugs were detected and quantified in each of the sweat patch screened-positive aliquots.

Although the sweat patch for subject 6 did not screen positive for cannabinoids, both urine specimens from this subject were positive for the drug. Therefore, the sweat patch was analyzed by MS and found to contain THC. In total, nine patch aliquots were positive. 
Table 4. Specimen summary

\begin{tabular}{|c|c|c|c|c|c|c|c|}
\hline ID \# & Patch & Urine Pre & Urine Post & Standard 1 & Standard 2 & Modified 1 & Modified 2 \\
\hline 1 & P2 & U1 & U2 & S1 & S2 & & \\
\hline 2 & & U1 & & S1 & & $\mathrm{L} 1$ & \\
\hline 3 & & U1 & & S1 & & L1 & \\
\hline 4 & P2 & U1 & & $\mathrm{S} 1$ & & & \\
\hline 5 & P2 & U1 & $\mathrm{U} 2$ & S1 & S2 & $\mathrm{L} 1$ & \\
\hline 6 & P2 & U1 & $\mathrm{U} 2$ & S1 & S2 & $\mathrm{L} 1$ & \\
\hline 7 & P2 & U1 & $\mathrm{U} 2$ & S1 & S2 & L1 & \\
\hline 8 & P2 & U1 & $\mathrm{U} 2$ & S1 & S2 & $\mathrm{L} 1$ & \\
\hline 9 & $\mathrm{P} 2$ & U1 & $\mathrm{U} 2$ & S1 & S2 & L1 & \\
\hline 10 & P2 & U1 & $\mathrm{U} 2$ & S1 & S2 & L1 & L2 \\
\hline 11 & P2 & U1 & $\mathrm{U} 2$ & S1 & S2 & $\mathrm{L} 1$ & L2 \\
\hline 12 & & U1 & $\mathrm{U} 2$ & S1 & & $\mathrm{L} 1$ & L2 \\
\hline 13 & P2 & U1 & $\mathrm{U} 2$ & S1 & S2 & L1 & \\
\hline 14 & $\mathrm{P} 2$ & U1 & $\mathrm{U} 2$ & S1 & & & L2 \\
\hline 15 & P2 & $\mathrm{U} 1$ & $\mathrm{U} 2$ & S1 & & & L2 \\
\hline 16 & & $\mathrm{U} 1$ & $\mathrm{U} 2$ & S1 & & & \\
\hline 17 & P2 & U1 & $\mathrm{U} 2$ & S1 & S2 & & L2 \\
\hline 19 & P2 & U1 & $\mathrm{U} 2$ & S1 & & & L2 \\
\hline 20 & $\mathrm{P} 2$ & U1 & $\mathrm{U} 2$ & S1 & & & \\
\hline 21 & & U1 & & & & & \\
\hline 22 & & U1 & & S1 & & & \\
\hline 23 & & U1 & $\mathrm{U} 2$ & S1 & S2 & & $\mathrm{L} 2$ \\
\hline 24 & P2 & U1 & $\mathrm{U} 2$ & S1 & & & L2 \\
\hline 25 & P2 & U1 & $\mathrm{U} 2$ & S1 & S2 & & L2 \\
\hline 26 & P2 & U1 & $\mathrm{U} 2$ & S1 & S2 & & L2 \\
\hline 27 & & U1 & $\mathrm{U} 2$ & S1 & S2 & & $\mathrm{L} 2$ \\
\hline 28 & & U1 & & & & L1 & \\
\hline 29 & P2 & U1 & $\mathrm{U} 2$ & S1 & & $\mathrm{L} 1$ & L2 \\
\hline 30 & & & U1 & S1 & & $\mathrm{L} 1$ & \\
\hline 31 & & U1 & U2 & & S2 & L1 & \\
\hline 32 & & U1 & & S1 & & L1 & \\
\hline 33 & P2 & U1 & $\mathrm{U} 2$ & S1 & S2 & $\mathrm{L} 1$ & \\
\hline
\end{tabular}




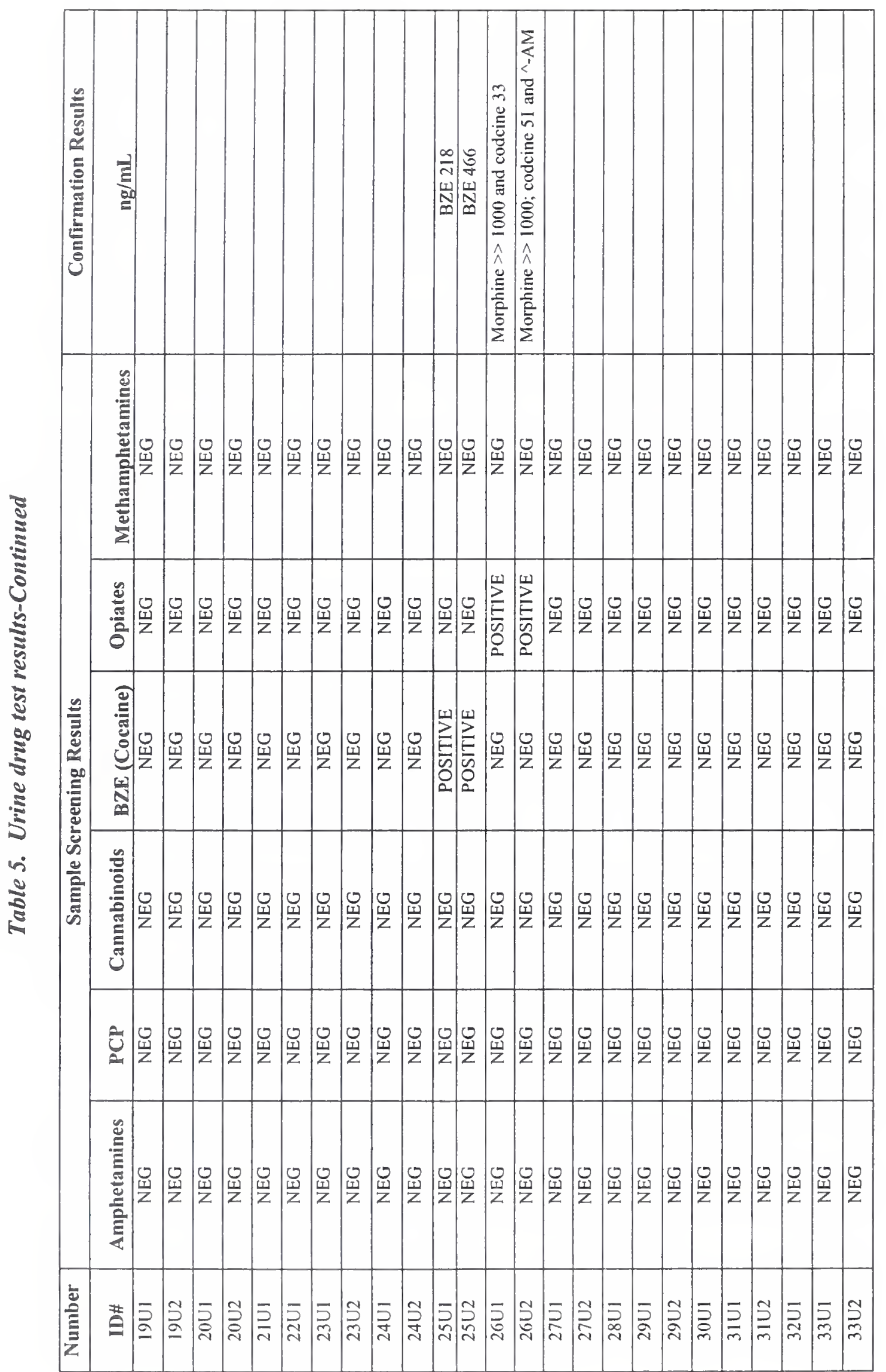




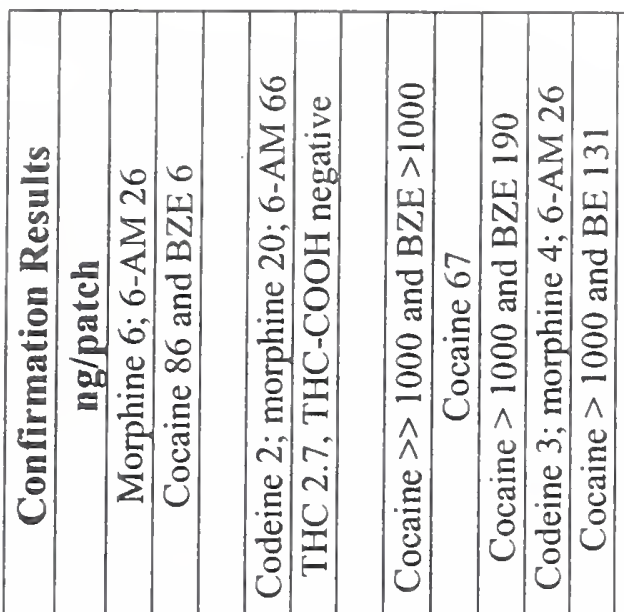

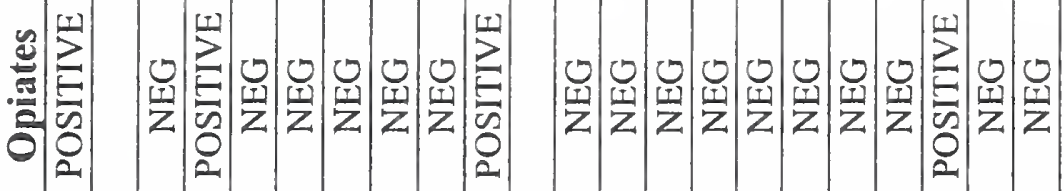

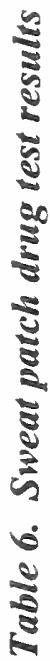
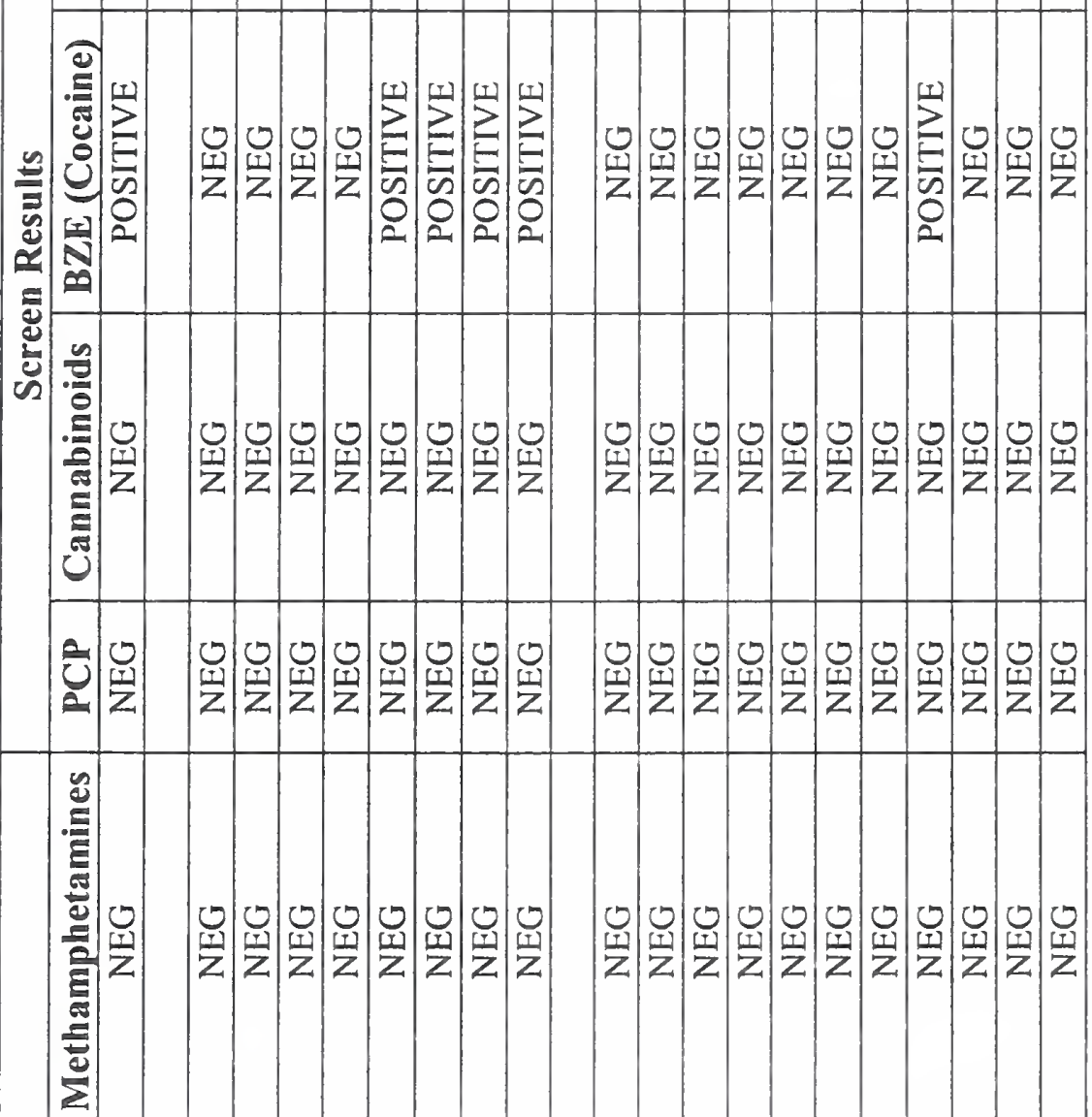

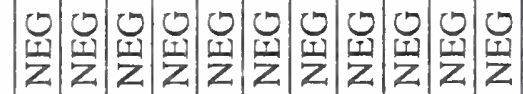

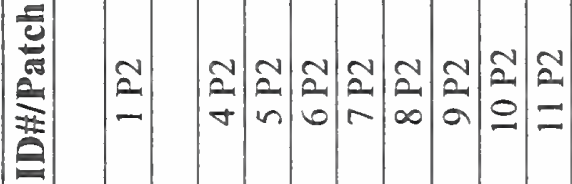

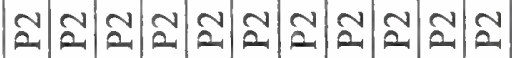

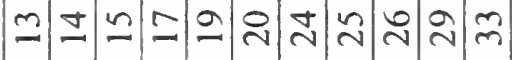




\subsubsection{Liquid Perspiration MS Results}

Results from the LP confirmation testing are shown in table 7. LP samples were selected for MS confirmation testing if $\mathrm{U} 1, \mathrm{U} 2$, or the sweat patch tested positive.

Subject 1 tested negative for opiates and cocaine in the urine, positive for both drug classes in the patch, and positive for opiates and cocaine in both LP specimens.

Subject 5 tested negative for opiates in the urine samples, positive in the patch, and positive in both LP specimens.

Subject 6 tested positive for marijuana in both urine samples, positive by MS in the patch, and negative in both LP specimens. Urine 2 was positive for PCP, the patch was negative, and both LP samples wee positive for this drug.

Subject 8 tested positive for cocaine in both urine samples, the patch, and in both LP specimens.

Subjects 9 and 10 tested negative for cocaine in both urine samples but positive in the patch and in both LP specimens.

Subject 11 tested positive for cocaine and opiates in only one of two urine samples and positive for both drugs in the patch. LP 1 contained only opiates, but LP 2 contained cocaine and opiates.

Subject 25 tested positive for cocaine in both urine samples, the patch, and both LP samples.

Subject 26 tested positive for opiates in both urine samples, the patch, and both LP samples. 
Table 7. Liquid perspiration results - MS

\begin{tabular}{|c|c|}
\hline Subject\#/Session 1 and Session 2 & Confirmation Results - $\mathrm{ng} / \mathrm{mL}$ \\
\hline $1 \mathrm{~S} 1$ & $\begin{array}{c}\text { Morphine } 42 \text {; codeine } 92 \\
\text { 6-AM } 90 \text { and heroin } 232 \\
\text { Cocaine and metabolites }=\text { negative }\end{array}$ \\
\hline $1 \mathrm{~S} 2$ & $\begin{array}{c}\text { Morphine } 15 \text {; codeine } 22 \\
\text { 6-AM } 1 \text { and heroin } 8 \\
\text { Cocaine and metabolites }=\text { negative }\end{array}$ \\
\hline $5 \mathrm{~S} 1$ & $\begin{array}{l}\text { Morphine 106; codeine } 255 \\
\text { 6-AM } 158 \text { and heroin } 2\end{array}$ \\
\hline $5 \mathrm{~S} 2$ & $\begin{array}{l}\text { Morphine } 85 ; \text { codeine } 38 \\
\text { 6-AM } 287 \text { and heroin } 4\end{array}$ \\
\hline $6 \mathrm{~S} 1$ & PCP 5 \\
\hline $6 \mathrm{~S} 2$ & PCP 8 \\
\hline $8 \mathrm{~S} 1$ & Cocaine 19; BZE 5 \\
\hline $8 \mathrm{~S} 2$ & Cocaine 132; BZE 19 \\
\hline $9 \mathrm{~S} 1$ & BZE 4 \\
\hline $9 \mathrm{~S} 2$ & BZE 1 \\
\hline $10 \mathrm{~S} 1$ & BZE 3 \\
\hline $10 \mathrm{~S} 2$ & BZE 3 \\
\hline $11 \mathrm{~S} 1$ & $\begin{array}{c}\text { Morphine } 9 ; \text { codeine } 16 \\
6-\mathrm{AM} 3 \\
\text { Cocaine and metabolites = negative }\end{array}$ \\
\hline $11 \mathrm{~S} 2$ & $\begin{array}{c}\text { Morphine } 11 \text {; codeine } 11 \\
\text { 6-AM } 2 \\
\text { BZE } 14 \\
\end{array}$ \\
\hline $25 \mathrm{~S} 1$ & Cocaine 16; BZE 62 \\
\hline $25 \mathrm{~S} 2$ & Cocaine 16; BZE 12 \\
\hline $26 \mathrm{~S} 1$ & Morphine 20; codeine 9 \\
\hline $26 \mathrm{~S} 2$ & Morphine 13 ; codeine 5 \\
\hline
\end{tabular}

\subsubsection{Liquid Perspiration Screening Results}

Results from the LP screen only testing are shown in table 8. LP samples were selected for screening only if the urine specimens and the sweat patch tested negative and the LP volume precluded a full screen and MS confirmation.

No samples screened positive for marijuana (THC/THCA), PCP or amphetamine.

Twenty-three LP specimens screened positive or border-line positive (POSITIVE?) for cocaine and metabolites. Twenty-three positive samples is a $70 \%$ positive rate. This rate is feasible given the population that was tested. However, results were not confirmed because the LP volume precluded MS confirmation. 


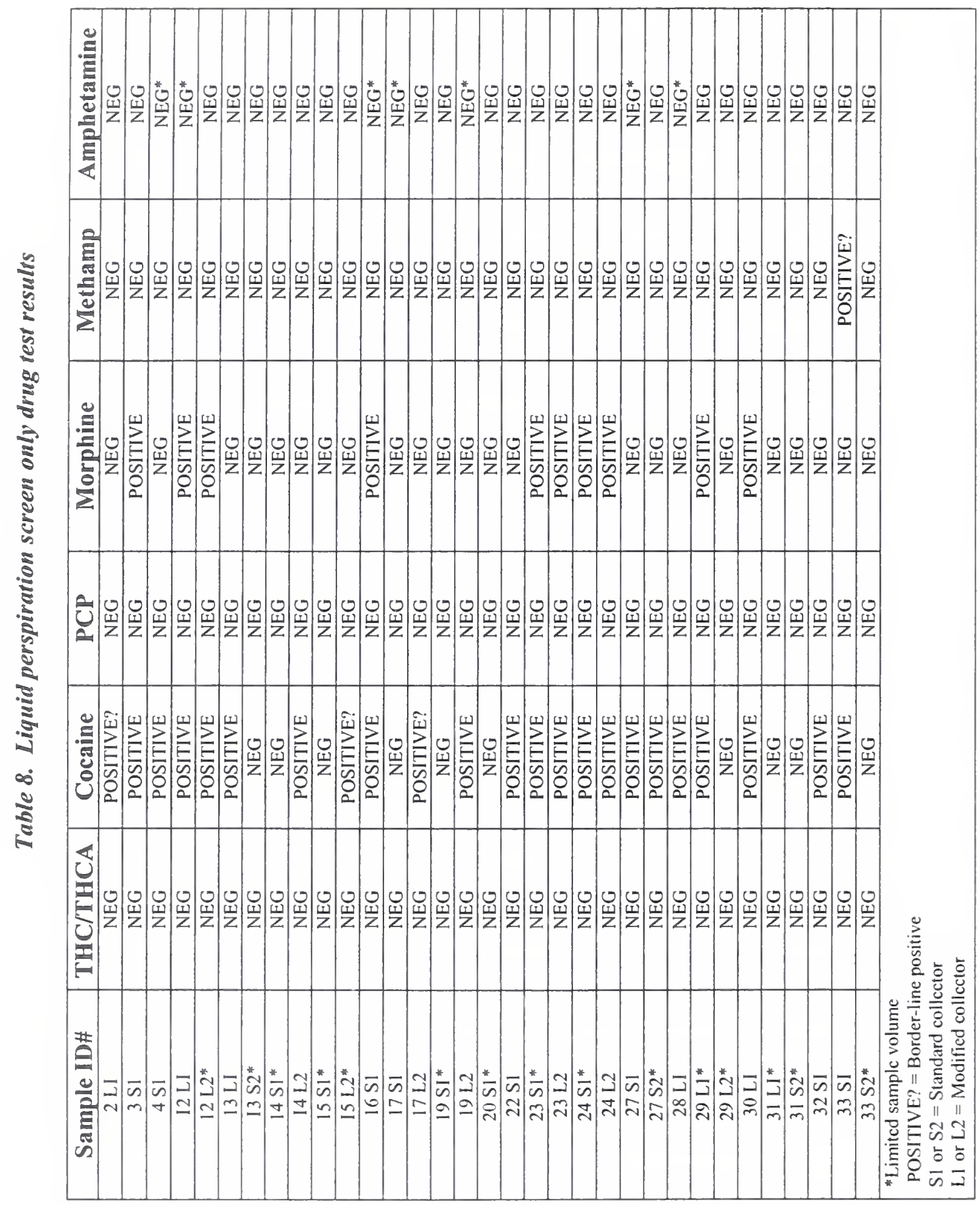


Ten LP specimens screened positive or border-line positive for opiates. Both LP specimens from 12,23 , and 24 tested positive. Even though these results were not confirmed by MS, they are very suggestive of opiate use by these subjects. Subjects 12 and 23 did not provide a sweat patch; however, both urine specimens were negative for opiates. The test results for subject 24 showed that the sweat patch and both urine specimens were negative for opiates.

A single LP specimen screened border-line positive for methamphetamine.

\subsubsection{A Comparison of MS Confirmed Urine, Sweat Patch, and LP Results}

Table 9 shows that 11 urine specimens tested negative when drugs were detected in either the sweat patch or the LP specimens. One sweat patch sample tested negative (subject 6) when the urine or LP specimens tested positive. Three LP specimens tested negative when the sweat patch or urine samples were drug positive. LP appears to be a good to excellent sample for the detection of opiates and cocaine, and it was consistent with urine and out performed the sweat patch for the detection of PCP. However, it was outperformed by the urine and the sweat patch for the detection of cannabinoids. No amphetamine(s) were detected in any of the samples. 
Table 9. Summary of positive test results

\begin{tabular}{|c|c|c|c|c|c|}
\hline ID\# & & & \multicolumn{3}{|c|}{ Positive Test Results } \\
\hline & Amps & PCP & Cannabs & BE (Cocaine) & Opiates \\
\hline $\begin{array}{l}\text { 1U1 } \\
1 \mathrm{U} 2 \\
\text { Patch } \\
\text { LP1 } \\
\text { LP2 }\end{array}$ & & & & $\begin{array}{c}\text { NEG } \\
\text { NEG } \\
\text { POSITIVE } \\
\text { POSITIVE } \\
\text { POSITIVE } \\
\end{array}$ & $\begin{array}{c}\text { NEG } \\
\text { NEG } \\
\text { POSITIVE } \\
\text { POSITIVE } \\
\text { POSITIVE }\end{array}$ \\
\hline $\begin{array}{c}\text { 5U1A } \\
5 U 1 B \\
5 U 2 \\
\text { Patch } \\
\text { LP1 } \\
\text { LP2 } \\
\end{array}$ & & & & & $\begin{array}{c}\text { NEG } \\
\text { NEG } \\
\text { NEG } \\
\text { POSITIVE } \\
\text { POSITIVE } \\
\text { POSITIVE }\end{array}$ \\
\hline $\begin{array}{l}6 \mathrm{U} 1 \\
6 \mathrm{U} 2 \\
\text { Patch } \\
\text { LP1 } \\
\text { LP2 } \\
\end{array}$ & & $\begin{array}{c}\text { NEG } \\
\text { POSITIVE } \\
\text { NEG } \\
\text { POSITIVE } \\
\text { POSITIVE }\end{array}$ & $\begin{array}{c}\text { POSITIVE } \\
\text { POSITIVE } \\
\text { POSITIVE } \\
\text { NEG } \\
\text { NEG } \\
\end{array}$ & & \\
\hline $\begin{array}{l}8 \mathrm{U} 1 \\
8 \mathrm{U} 2 \\
\text { Patch } \\
\text { LP1 } \\
\text { LP2 }\end{array}$ & & & & $\begin{array}{l}\text { POSITIVE } \\
\text { POSITIVE } \\
\text { POSITIVE } \\
\text { POSITIVE } \\
\text { POSITIVE }\end{array}$ & \\
\hline $\begin{array}{l}\text { 9U1 } \\
\text { 9U2 } \\
\text { Patch } \\
\text { LP1 } \\
\text { LP2 }\end{array}$ & & & & $\begin{array}{l}\text { NEG } \\
\text { NEG } \\
\text { POSITIVE } \\
\text { POSITIVE } \\
\text { POSITIVE } \\
\end{array}$ & \\
\hline $\begin{array}{l}\text { 10U1 } \\
\text { 10U2 } \\
\text { Patch } \\
\text { LP1 } \\
\text { LP2 } \\
\end{array}$ & & & & $\begin{array}{c}\text { NEG } \\
\text { NEG } \\
\text { POSITIVE } \\
\text { POSITIVE } \\
\text { POSITIVE } \\
\end{array}$ & \\
\hline $\begin{array}{l}11 \mathrm{U} 1 \\
11 \mathrm{U} 2 \\
\text { Patch } \\
\text { LP1 } \\
\text { LP2 } \\
\end{array}$ & & & & $\begin{array}{c}\text { NEG } \\
\text { POSITIVE } \\
\text { POSITIVE } \\
\text { NEG } \\
\text { POSITIVE } \\
\end{array}$ & $\begin{array}{c}\text { NEG } \\
\text { POSITIVE } \\
\text { POSITIVE } \\
\text { POSITIVE } \\
\text { POSITIVE }\end{array}$ \\
\hline $\begin{array}{l}25 \mathrm{U} 1 \\
25 \mathrm{U} 2 \\
\text { Patch } \\
\text { LP1 } \\
\text { LP2 } \\
\end{array}$ & & & & $\begin{array}{l}\text { POSITIVE } \\
\text { POSITIVE } \\
\text { POSITIVE } \\
\text { POSITIVE } \\
\text { POSITIVE }\end{array}$ & \\
\hline $\begin{array}{l}26 \mathrm{U} 1 \\
26 \mathrm{U} 2 \\
\text { Patch } \\
\text { LP1 } \\
\text { LP2 }\end{array}$ & & & & & $\begin{array}{l}\text { POSITIVE } \\
\text { POSITIVE } \\
\text { POSITIVE } \\
\text { POSITIVE } \\
\text { POSITIVE }\end{array}$ \\
\hline
\end{tabular}




\section{DISCUSSION}

The pilot study achieved several important objectives. As a preparation for the main field study, the pilot study demonstrated that an LP collection device could be used to harvest LP specimens in a criminal justice setting, and that drugs of abuse could be detected in LP specimens using available analytic procedures. The study also identified challenges, both practical and analytic, to the use of the LP method for drug testing. The $25 \mathrm{~min}$ to 30 min collection time may be inconvenient in many settings, and the small volume of LP collected poses significant technical difficulties in the analysis; both issues deserve close attention as we prepare for the main field study. Because the results indicated that the larger, specially engineered collector was capable of collecting larger volumes at a faster rate than the standard collector, the modified (and similarly modified devices) will be considered for use in the field test.

The arrestees appeared to have had few (if any) problems with the data collection procedures. The recruitment of subjects and the collection of specimens proceeded without any serious impediments. The management and staff of the pretrial agency were helpful and supportive of the research project, and most arrestees approached to participate in the research volunteered to do so. Subjects' ratings of the different collection procedures indicated that the LP procedures were perceived as no more discomforting or unpleasant than a urine collection and the sweat patch, and that the LP procedures were viewed as significantly less embarrassing than a urine collection.

Substantial strides were made in the development and validation of the analytic methods for screening and confirmation of drugs in LP specimens. Preliminary IA experiments showed that the EIA kits were more promising for drug screening than RIA, particularly for the detection of amphetamine, methamphetamine, THC, and THC metabolite. An examination of the MS confirmation procedures (GC/MS, LC/MS, and LC/MS/MS) found that specific and sensitive methods could be developed for the analysis of LP. However, inefficiencies in THC and THC$\mathrm{COOH}$ ionization using LC/MS/MS has led to continued research for an alternative method. Currently, we are using negative ion chemical ionization GC/MS and exploring the use of derivatization and then LC/MS/MS analysis.

The LP specimens of nine subjects yielded MS confirmed positives for drugs. Eight of these subjects tested positive for cocaine/metabolites and opiates/metabolites (or both); one tested positive for PCP. In only one subject did the urine tests detected a drug (cannabinoids) that was not detected in the LP specimens (table 9). In four subjects, LP tests detected drugs (two opiate and two cocaine positives) that the urine tests did not detect. However, in all four subjects the sweat patch specimen tested positive for drugs detected in LP. In addition, the LP screening tests yielded an astonishing $70 \%$ positive rate for cocaine (table 8). Unfortunately, because of the limited volume of the LP specimens these positive screening results could not be confirmed. Nonetheless, these findings indicate that not only is LP a promising matrix for drug testing, but that it may be superior to urine for detecting cocaine and opiate use. The results suggest that LP may not be as effective as urine in detecting cannabinoids. However, only one subject tested positive for cannabinoids. The very low number of positives found for THC and THC-COOH, as well as for PCP and amphetamines in the pilot study, precludes drawing any conclusions in this regard at this time. 


\section{CONCLUSIONS}

Several conclusions were reached from this pilot study as follows:

- Liquid perspiration can be harvested in criminal justice settings using the modified or standard collector. Minimal training was required for the project staff to effectively use the collection apparatus, and the device was readily accepted by both agency staff and arrestees.

- The modified collector can be used in criminal justice settings to collect LP specimens in a noninvasive, totally observed manner, and the procedure was well tolerated by the subjects. Subjects found the modified collector to be no more unpleasant and significantly less embarrassing than a urine collection.

- Existing, commercially available drug screening methods can be used effectively to screen for drugs of abuse in LP specimens. Both EIA and RIA showed promise. EIA was selected due to its better sensitivity for amphetamines and cannabinoids.

- MS procedures were developed and validated for confirmation of drugs of abuse in LP.

- Drugs of abuse and their metabolites are excreted in LP. This was suggested by the research that has been reported using the sweat patch, but had not actually been demonstrated until this pilot study was performed.

- LP may be a preferable specimen to urine for the detection of drug use by arrestees in the criminal justice system (tables 8 and 9). These tables show that LP was very effective in detecting drug use by arrestees. Screening results show that several additional subjects were identified as cocaine and opiate positive using LP testing. MS results identified six incidences in which the LP was drug positive and the corresponding urine specimen tested negative.

- The volume of LP collected is a limitation. The volume is sufficient to screen for the drugs of abuse or to perform a limited screen and a confirmation of no more than one or two drugs. The specially engineered collector appears to collect larger volumes at a faster rate than the standard collector. Modified LP devices need to be further explored for use in the field test.

- Further study of LP is needed to fully understand the advantages and limitations of the specimen and the collection technique. For example, no pilot-study arrestees tested positive for amphetamine(s), only one tested positive for cannabinoids, and one for PCP. This is an insufficient number of subjects and test results from which to draw significant conclusions. Also, THC and THC-COOH were not detected in any LP specimens, while THC-COOH was detected in the subject's urine and THC was detected in his sweat patch. LP appeared to be a superior specimen to urine for the detection of cocaine and opiates, but again a limited number of subjects and specimens were tested. 


\section{REFERENCES}

J. Baer and J. Booher, "The Patch: An Alternative for Drug Testing in the Criminal Justice System," Federal Probations, 58, 29 (1994).

W. Baumgartner, C. Black, and P. Jones, "Radioimmunoassay of Hair Cocaine in Hair." J. Nuc. Med., 23 (1982).

D. Blank and D. Kidwell, "Decontamination Procedures for Drugs of Abuse in Hair: Are They Sufficient”? Forensic Sci. Int., 70, 13 (1995).

M. Burns and R. Baselt, "Monitoring Drug Use With a Sweat Patch: An Experiment With Cocaine." J. Anal. Toxicol., 19, 41 (1995).

E.P. Carter, A.D. Barrett, A.F. Heeley, and J.A. Kuzemko. Improved Sweat Testing Method for the Diagnosis of Cystic Fibrosis. Arch Dis Children, 59, 919-922 (1984).

R.F. Cook, A.D. Bernstein, T.L. Arrington, C.M. Andrews, and G.A. Marshall, "Methods for Assessing Drug Use Prevalence in the Workplace: A Comparison of Self-Report, Urinalysis and Hair Analysis." The International Journal of the Addictions, 30 (4), $403-$ 326 (1995).

R.F. Cook, A.D. Bernstein, and C.M. Andrews, "Assessing Drug Use in the Workplace: A Comparison of Self-Report, Urinalysis and Hair Analysis." In Harrison and Hughes (eds.), The Validity of Self-Reported Drug Use: Improving the Accuracy of Survey Estimates. NIDA Research Monograph 167, NIH Pub. No. 96-4147, Washington, DC (1996).

E. Cone, W. Darwin, and W. Wang, "The Occupance of Cocaine, Heroin and Metabolites in Hair of Drug Abusers," Forensic Sci. Int., 63, 55 (1993).

E. Cone, "Session II. Drug Monitoring in Saliva, Saliva Testing for Drugs of Abuse." Saliva as a Diagnostic Fluid, Vol. 694, D. Malamud, and K. Tabak, The New York Academy of Sciences, New York, 91-127 (1993).

D. Crouch, M. Peat, B. Finkle, and D. Chinn, "Drugs and Driving: A Systematic Analytical Approach.” J. Forensic Sci., 38, 4, 945 (1983).

D. Crouch, M. Alburgues, A. Spanbauer, D. Rollins, D. Moody, and A. Chasin, "Analysis of Cocaine and Its Metabolites From Biological Specimens by Solid Phase Extraction and Chemical Ionization Mass Spectrometry." J. Anal. Toxicol., 19, 6 (1995).

R. Dembo, L. Williams, E.D. Wish, and J. Schmeidler, "Urine Testing of Detained Juveniles to Identify High-Risk Youth." NIJ Research in Brief, Washington, DC: U.S. Department of Justice (1990).

Department of Health and Human Services. "Mandatory Guideline for Federal Workplace Testing Programs." Federal Register, 58 (14) 6062-72 (1993). 
Product Inserts, Diagnostic Products Corporation, Los Angeles, CA. Amphetamine, April 1992;

Methamphetamine, October 1992; Cannabinoids, April 1993; Cocaine, March 1997;

Morphine, March 1997, and Phencyclidine, March 1997.

R. DuPont and W. Baumgartner, "Drug Testing by Urine and Hair Analysis: Complementary

Features and Scientific Issues." Forensic Sci. Int., 70, 63, (1995).

J. Fay, R. Fogerson, D. Schoendorfer, S. Niedbala, and V. Speihler. "Detection of

Methamphetamine in Sweat by EIA and GC-MS." J. Anal. Toxicol., 29, 398 (1996).

R. Fogerson, D. Schoendorfer, J. Fay, and V. Spieler. Qualitative Detection of Opiates in Sweat by EIA and GC-MS. J. Anal. Tox., 21, 451-458, October 1997.

R. Foltz, A. Fentiman, Jr., and R. Foltz, Research Monograph Series, GC/MS Assays for Abused Drugs in Body Fluids, 32, Department of Health and Human Services, Rockville, MD (1980).

R. Foltz, K. McGinnis, and D. Chinn, "Quantitative Measurement of Delts-9-Tetrahydrocannabinol and its Two Metabolites in Physiological Specimens Using Capillary Column Gas Chromatography Negative Ion Chemical Ionization Mass Spectrometry." Biomedical Mass Spectrometry, 10, 316 (1983).

R. Goldblum, L. Goldblum, and W. Piper, "Barbiturate Concentrations in the Skin and Hair of Guinea Pigs." J. Invest. Derm., 22 (1954).

J.S. Goldkemp and D. Weiland, "Assessing the Impact of Dade County's Felony Drug Court." NIJ Research in Brief, Washington, DC: U.S. Department of Justice (1993).

K. Hammond, N. Turcios, and L. Givson, "Clinical Evaluation of the Macroduct Sweat Collection System and Conductivity Analyzer in the Diagnosis of Cystic Fibrosis." J. Pediatrics, 124, 255 (1994).

M. Harkey and G. Henderson, "Hair Analysis for Drugs of Abuse," Adv. Anal. Tox., 2, 298 (1989).

L. Henderson, M. Powell, W. Hannon, B. Miller, M. Martin, R. Hanzlik, D. Vroon, and W. Sexon, "Radioimmunoassay Screening of Dried Blood Spot Materials for Benzoylecgonine." J. Anal. Toxicol., 17, 42 (1993).

A. Jenkins, J. Oyler, and E. Cone, "Comparison of Heroin and Cocaine Concentrations in Saliva With Concentrations in Blood and Plasma," J. Anal. Toxicol., 19, 359 (1995).

R. Joseph, T. Su, and E. Cone, "In Vitro Binding Studies of Drugs to Hair: Influence of Melanin and Lips on Cocaine Binding to Caucasoid and Africoid Hair." Anal. Toxicol., 20, 338 (1996).

D. Kidwell, "Analysis of Phencyclidine and Cocaine in Human Hair by Tandem Mass Spectrometry," J. Forensic Sci., 59, 29 (1993). 
D.A. Kidwell, J.C. Holland, and S. Athanaselis, "Testing for Drugs of Abuse in Saliva and Sweat." Journal of Chromatography. Pages 111-1135 (1998).

P. Kintz, A. Tracqui, C. Jamey, and Mangin. "Detection of Codeine and Phenobarbital in Sweat Collected With a Sweat Patch." J. Anal. Toxicol., 20, 197 (1996).

Y. Kuno, Human Perspiration. C.C. Thomas, Springfield, IL (1956).

M. Levine, B. Baum, R. Turner, W. Jusko, R. Milsap, J. Wilson, and E. Silbergeld, "Session 1. Principles of Salivary Gland Fluid Secretion/Overview of Pharmacology." Saliva as a Diagnostic Fluid, Col. 694, D. Malamud, and L. Tabak, The New York Academy of Sciences, New York, pp. 11-62 (1993).

T. Mieczkowski, H. Landress, R. Newel, and S. Coletti. "Testing Hair for Illicit Drug Use." NIJ Research in Brief, Washington, DC: U.S. Department of Justice (1993).

T. Mieczkowski and K. Lersch. "Drug Testing in Criminal Justice: Evolving Uses, Emerging Technologies.” NIJ Journal, December 1997.

D. Moody, L. Rittenhouse, and K. Moni. "Analysis of Cannabinoids, Vol. I. Comparison of RIA and GC/MS Analysis of Blood." J. Anal. Toxicol., 16, 297 (1992).

National Institute of Justice, The Future of Drug Testing. Meeting in Washington, DC, March 6-7, 1996.

C. L. O'Neal, D.J. Crouch, D.E. Rollins, and A.A. Fatah. The Effects of Collection Methods on Oral Fluids Codeine Concentrations. J. Anal. Tox., 23, 436-452, October 2000.

PharmChek®, PharmChem Laboratories, Inc., Menlo Park, CA 94025-1435 (1996).

B.A. Reaves (1992). "Drug Enforcement by Police and Sheriffs Departments," (1990). BJS Special Report, Washington, DC: U.S. Department of Justice.

M. Slawson, D. Wilkins, R. Foltz, and D. Rollins, "Quantitative Determination of Phencyclidine in Pigmented and Nonpigmented Hair by Positive Chemical Ionization Ion Trap Mass Spectrometry," Anal. Toxicol., 20, 350 (1996).

F. Smith and D. Pomosini. "Detection of Phenobarbital in Blood Stains, Semen, Seminal Stains, Saliva, Saliva Stains, Perspiration Stains and Hair.” J. Forensic Sci., 26, 582 (1981).

L. Sniegoski and M. Welch, "Interlaboratory Studies on the Analysis of Hair for Drugs of Abuse: Results From the Fourth Exercise." J. Anal. Toxicol., 20, 242 (1996).

V. Speihler, J. Fay, R. Fogerson, D. Schoendorfer, and S. Niedbala, "Enzyme Immunoassay Validation for Qualitative Detection of Cocaine in Sweat." Clin Chem., 42, 34 (1996).

SPSS, Inc. SPSS Advanced Models 10.0, Prentice Hall (1999). 
Package Inserts, STC Diagnostics, Bethlehem, PA 18018, February 1996.

Package Inserts, STC Technologies, Inc., Bethlehem, PA 18018. Cannabinoids, August 1997;

Methamphetamine, January 1997; Opiates, January 1997 and PCP, December 1996.

O. Suzuki, H. Hattori, and M. Asano, "Detection of Methamphetamine and Amphetamine in a Single Human by Gas Chromatography/Chemical Ionization Mass Spectrometry." J. Forensic Sci., 29, 611 (1984).

S. Turner, J. Petersilia, and E. Deschenes, "The Implementation and Effectiveness of Drug Testing in Community Supervision: Results of an Experimental Evaluation." In D.L. MacKenzie and C.D. Uchida (Eds.), Drugs and Crime: Evaluating Public Policy Initiatives. Thousand Oaks, CA: Sage Publication (1994).

V. Valkovic, "Human Hair Growth," Human Hair, Vol. 1, Chapter 2. CRC Press, Inc., Boca Raton (1988).

V. Valkovic, "Forensic Applications of Hair Analysis," Human Hair, Vol. 2, Chapter 9. CRC Press, Inc., Boca Raton (1988).

C. Visher, "Pretrial Drug Testing." NIJ Research in Brief, Washington, DC: U.S. Department of Justice (1992).

W. Wang and E. Cone, "Testing Human Hair for Drugs of Abuse. IV Environmental Cocaine Contamination and Washing Effects," Forensic Sci. Int., 70, 39 (1995).

L. Webster and W. Barlow, "New Approach to Cystic Fibrosis Diagnosis by Use of an Improved Sweat-Induction/Collection System and Osmometry." Clin Chem., 27, 385 (1981).

L. Webster and H. Lochlin, "Cystic Fibrosis Screening by Sweat Analysis." Medical Journal of Australia, 1, 923 (1977).

L. Webster, "Laboratory Diagnosis of Cystic Fibrosis." CRC Critical Reviews in Clinical Laboratory Sciences, 18, 313 (1983).

M. Welch, L. Sniegoski, and C. Allgood, "Interlaboratory Comparison Studies on the Analysis of Hair for Drugs of Abuse," Forensic Sci. Int., 63, 295 (1993).

D. Wilkins, H. Haughey, E. Cone, M. Heusits, R. Foltz, and D. Rollins, "Quantitative Analysis of THC, 11-OH-THC and THC-COOH in Human Hair by Negative Ion Chemical Ionization Mass Spectrometry." J. Anal. Toxicol., 19, 483 (1995). 

